\title{
New Peptidomimetic Boronates for Selective Inhibition of the Chymotrypsin-like Activity of the 26S Proteasome
}

\author{
Zhang $\mathrm{X}^{* 13}$, Adwal $\mathrm{A}^{\zeta * 2}$, Turner $\mathrm{AT}^{2}$, Callen $\mathrm{DF}^{2}$, Abell $\mathrm{AD}^{13}$ \\ * Equal first authors \\ $\zeta$ Corresponding author, email: alaknanda.alaknanda@adelaide.edu.au \\ ${ }^{1}$ Department of Chemistry, The University of Adelaide, North Terrace, Adelaide SA, \\ Australia \\ ${ }^{2}$ Centre for Personalised Cancer Medicine, Discipline of Medicine, The University of \\ Adelaide, North Terrace, Adelaide SA, Australia \\ ${ }^{3}$ ARC Centre of Excellence for Nanoscale BioPhotonics, Institute of Photonics and \\ Advanced Sensing, Department of Chemistry, The University of Adelaide, South \\ Australia, 5005
}

\section{Table of Contents:}
a. General Information
Page S2
b. In Vitro Proteasome Activity Assay
Page S2
c. In Vitro a-Chymotrypsin Activity Assay
Page S2
d. Cell Viability Assay
Page S2
e. Western Blot Analysis
Page S2
f. The Preparation of Boronates 1a,b and 2a,b
Page S3
g. Chemical Syntheses
Page S3
h. $\quad{ }^{1} \mathrm{H}$ and ${ }^{13} \mathrm{C}$ NMR Spectra
Page S6
i. HPLC Traces for Compounds $\mathbf{1 a}, \mathbf{b}$ and $\mathbf{2 a}, \mathbf{b}$
Page S10
j. Dose Response Curves for the Inhibition of the 20S Proteasome
Page S1 1
k. Dose Response Curves for Cell Cytotoxicity Experiments
Page S14
1. Ubiquitin Accumulation Western Blot for Compounds 1a, 2a, Bortezomib and Carfilzomib
Page S19
m. References
Page S20 


\section{a. General Information}

Bortezomib (Selleckchem, Houston, TX, USA), Carfilzomib (Selleckchem, Houston, TX, USA), or in-house generated derivatives were dissolved in $10 \mathrm{mM}$ DMSO and stored at $-20^{\circ} \mathrm{C}$. Antibodies used for western blot analysis included a mouse anti-tubulin (Sigma), antiubiquitin (Cell Signalling), sheep anti-mouse IgG-HRP (GE, USA), or donkey anti-rabbit IgG-HRP (GE, USA). All human cell lines (WE68, RD-ES, SKOV3, KGN, MCF7, MDA-MB-468, NCI-H929, U266, MCF-10A, and IMR-90) were purchased from American Type Tissue Culture. WE-68, NCI-H929, U266, MCF7 and LCL cell lines (established from a normal individual) were grown in RPMI-1640 media. RD-ES, MDA-MB-468, SKOV-3, KGN and a primary human embryonic fibroblast cell line were grown in Dulbecco's Modified Eagle's Medium (DMEM). The medium was supplemented with 10\% FCS, 1\% PSG and 10 mM HEPES. MCF-7 cells were supplemented with $1 \%$ insulin. All cells were maintained at $37^{\circ} \mathrm{C}$ in a humidified atmosphere of $5 \% \mathrm{CO}_{2}$.

\section{b. In Vitro Proteasome Activity Assay}

Proteasome CT-L, C-L and T-L activities were determined using hydrolysis of specific short peptide substrates conjugated to the fluorescent tag 7-amido-4-methylcoumarin (AMC). Fluorogenic CT-L substrate (Suc-Leu-Leu-Val-Tyr-AMC) were purchased from Boston Biochem (Cambridge, MA, USA). The purified 20S proteasome, T-L and C-L fluorogenic substrates (Bz-Val-Gly-Arg-AMC and Ac-nLPnLDAMC) were purchased from Enzo Life Sciences (Farmingdale, NY, USA). Purified mouse immunoproteasome was purchased from AdipoGen (San Diego, USA). The proteasome $(0.2 \mu \mathrm{g})$ was pre-incubated with the indicated concentrations of inhibitors at $37{ }^{\circ} \mathrm{C}$ for 15 minutes and subsequently added to the AMC-labelled substrate peptide $(50 \mu \mathrm{M})$ in assay buffer $(20 \mathrm{mM}$ Tris- $\mathrm{HCl}, \mathrm{pH} 7.5,0.5 \mathrm{mM}$ EDTA, and $0.001 \%$ SDS (w/v)) for a further 2 hours. Fluorescent substrate cleavage by the 20S proteasome was linear during this incubation period. Hydrolysed AMC was subsequently detected with the Synergy ${ }^{\mathrm{TM}}$ H4 Hybrid Multi-Mode Microplate Reader (BioTek, USA) at excitation/emission wavelengths of $390 / 460 \mathrm{~nm}$. Hydrolysis activity was measured as relative fluorescence units allowing $\mathrm{IC}_{50}$ values to be calculated that represented half of the maximal inhibitory activity of the proteasome. A minimum of three biological replicates was performed for each data point.

\section{c. In Vitro $\alpha$-chymotrypsin Activity Assay}

The activity of $\alpha$-chymotrypsin was assayed spectrophotometrically at $25{ }^{\circ} \mathrm{C}$ using Synergy H4 Hybrid Multi-Mode Microplate Reader (Bio-Tek Instruments, Inc.). A solution of $\alpha$-chymotrypsin $(21.9 \mu \mathrm{g} / \mathrm{mL})$ in $1 \mathrm{mM}$ aqueous $\mathrm{HCl}$ was prepared fresh by a 1:40 dilution of a stock solution $(874 \mu \mathrm{g} / \mathrm{mL})$ in $1 \mathrm{mM}$ aqueous $\mathrm{HCl}$ and kept on ice. A 1:100 dilution of the $21.9 \mu \mathrm{g} / \mathrm{mL}$ solution in ice-cold $1 \mathrm{mM}$ aqueous $\mathrm{HCl}$ was prepared immediately before the start of each measurement. The assay was conducted in black 96-well plates as below: To each well were added Ala-Ala-Phe-7-AMC (Sigma Aldrich, Castle Hill, NSW) substrate in DMSO ( $5 \mu \mathrm{L}$, final concentrations $=0.25,0.5 \mathrm{mM})$, $\alpha$-chymotrypsin in $1 \mathrm{mM}$ aqueous $\mathrm{HCl}(10 \mu \mathrm{L}$, final concentration $=4 \mathrm{nM})$, an inhibitor $(0.25 \mathrm{nM}-25 \mathrm{nM})$ in $\mathrm{DMSO}(10 \mu \mathrm{L})$ and $\mathrm{N}$ [Tris(hydroxymethyl)methyl]-2-aminoethanesulfonic acid (TES) buffer (50 mM, pH 8.0, adjusted with $\mathrm{NaOH})(175 \mu \mathrm{L})$. The excitation and emission wavelengths of the substrate were $380 \mathrm{~nm}$ and $460 \mathrm{~nm}$ respectively. Progress curves were monitored over 10 min for each concentration of every inhibitor. The Ki values of inhibitors were determined graphically according to Dixon ${ }^{1}$ using mean values of relative rates obtained from triplicate measurements at two different concentrations.

\section{d. Cell Viability Assays}

Cell viability assays were performed as previously described ${ }^{2}$. Briefly, cells were seeded in 96 -well microtiter plates at a density of $3 \times$ $10^{4}$ cells per well in the presence of the indicated proteasome inhibitor. Cells were harvested 48 hours post-treatment, centrifuged at 1,300 $\times g$, washed in phosphate-buffered saline (PBS), and stained with 7AAD solution $(2 \mu \mathrm{g} / \mathrm{mL})$ (7-amino-actinomycin-D, Invitrogen, Carlsbad, CA) for 10 minutes at RT. Viable cells were determined using a FACS Calibur flow cytometer (Becton Dickinson Immunocytometry Systems) and analyzed with FLOWJO (Tree Star, Inc.) and GraphPad Prism (GraphPad Software Inc.). For each experiment each datapoint was in triplicate and the $\mathrm{LD}_{50}$ calculated from three biological replicates.

\section{e. Western blot analysis}

Western blot analysis was performed as previously described ${ }^{3}$. Whole protein lysates $(5-20 \mu g)$ were resolved using SDS PAGE electrophoresis, and probed overnight at $4{ }^{\circ} \mathrm{C}$ with the anti-Ubiquitin primary antibody (3933, 1:1000, Cell Signaling Technology). Chemiluminescent detection of protein was done using appropriate secondary antibody conjugated with horseradish peroxidise (Amersham) and the enhanced chemiluminescence kit according to the manufacturer's instructions (Amersham). 


\section{f. The Preparation of Boronates 1a,b and 2a,b}

Scheme 1. Synthesis of compounds $1 \mathrm{a}, \mathrm{b}$.

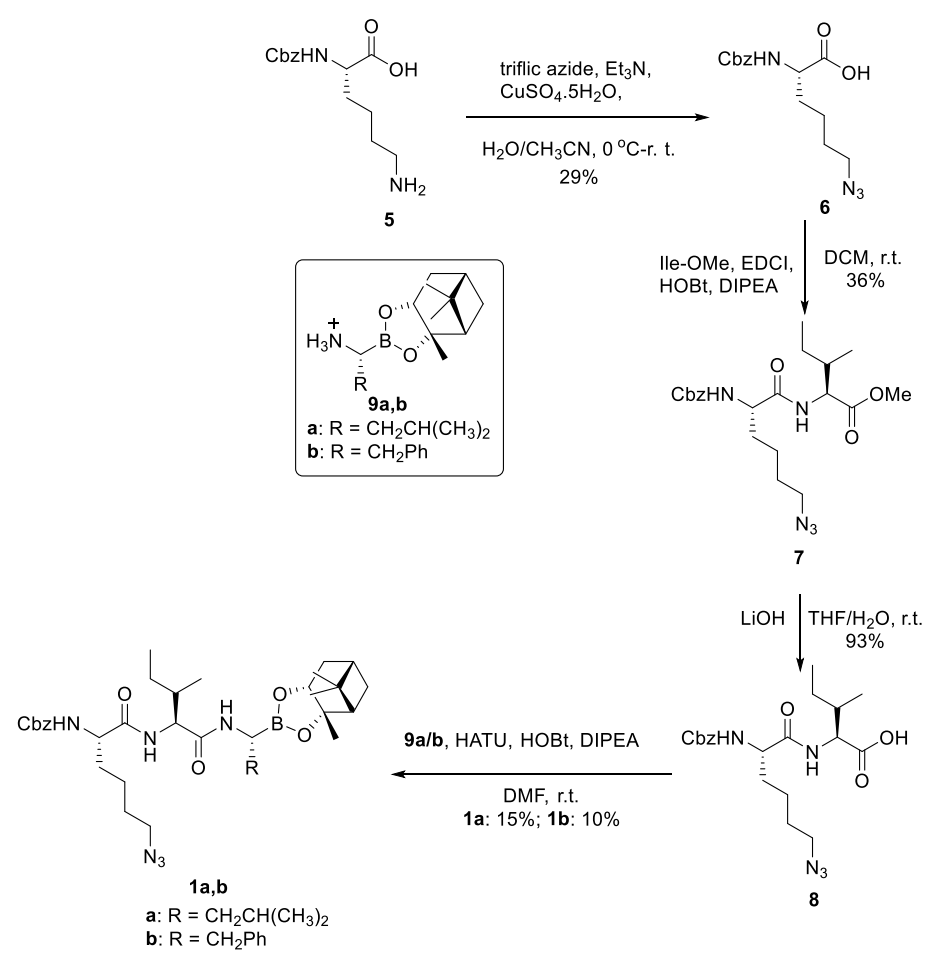

Scheme 2. Synthesis of compounds $2 a, b$.
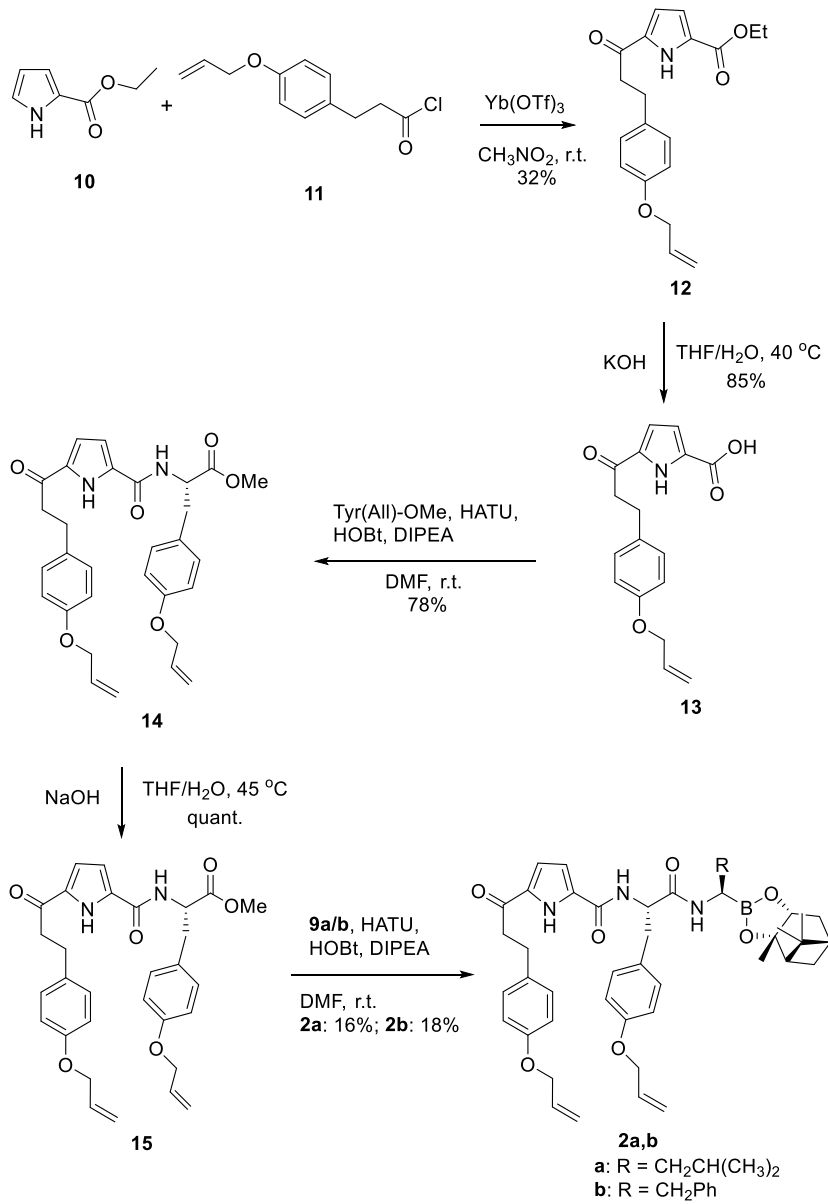

The key azide 6 was prepared by reacting Cbz-Lys-OH (5) with freshly prepared triflic azide under basic conditions. Subsequent EDCImediated coupling of azide $\mathbf{6}$ to Ile-OMe gave the dipeptide 7. Hydrolysis of the methyl ester of 7 in the presence of LiOH gave the free acid 8 in an excellent yield of $93 \%$. This free acid was then coupled with amino boronate $\mathbf{9 a}, \mathbf{b}^{4}$ in the presence of HATU, HOBt and DIPEA to give the target inhibitors 1a,b (see Scheme 1).

The alternative boronate esters $\mathbf{2 a}$ and $\mathbf{2 b}$ were synthesised in 5 steps from starting materials $\mathbf{1 0}$ and $\mathbf{1 1}$ prepared according to literature methods (see Scheme 2). ${ }^{5}$ In particular, $\mathrm{Yb}(\mathrm{OTf})_{3}$-catalysed Friedel-Craft acylation of pyrrole $\mathbf{1 0}$ with acid chloride $\mathbf{1 1}$ gave the key dipeptide-mimic 12. Hydrolysis of the methyl ester of 12 with $\mathrm{KOH}$ gave carboxylic acid 13, which was subsequently coupled with Tyr(All)-OMe in the presence of HATU, HOBt and DIPEA to give diene 14 in 78\% yield over two steps. The methyl ester of diene 14 was hydrolysed with $\mathrm{NaOH}$ to give free acid $\mathbf{1 5}$ in excellent yield. HATU-mediated coupling of $\mathbf{1 5}$ with amino boronates $\mathbf{9 a , b}$ gave the target inhibitors 2a,b.

\section{g. Chemical Syntheses}

General Information: Unless otherwise indicated, all starting materials and anhydrous solvents were purchased from Sigma Aldrich (NSW, Australia) and were used without further purification. ${ }^{1} \mathrm{H}$ and ${ }^{13} \mathrm{C}$ NMR spectra were recorded on a Varian $500 \mathrm{MHz}$ and a Varian Inova $600 \mathrm{MHz}$ instruments in the indicated solvents. Chemical shifts are reported in ppm $(\delta)$. Signals are reported as s (singlet), br s (broad singlet), d (doublet), dd (doublet of doublets), $\mathrm{t}$ (triplet) or $\mathrm{m}$ (multiplet). High resolution mass spectra were collected using an LTQ Orbitrap XL ETD using flow injection, with a flow rate of $5 \mu \mathrm{L} / \mathrm{min}$. Where indicated compounds were analyzed and purified by reverse phase HPLC, using an HP 1100 LC system equipped with a Phenomenex C-18 column $(250 \times 4.6 \mathrm{~mm})$ for analytical traces and a Gilson GXPrep HPLC system equipped with a Phenomenex C18 column $(250 \times 21.2 \mathrm{~mm}) . \mathrm{H}_{2} \mathrm{O} / \mathrm{TFA}(100 / 0.1 \mathrm{by} \mathrm{v} / \mathrm{v}, \mathrm{A})$ and ACN/TFA $(100 / 0.08$ by $\mathrm{v} / \mathrm{v}, \mathrm{B})$ solutions were used as aqueous and organic buffers.

Boronic ester inhibitor 1a: To a solution of free acid $8(50 \mathrm{mg}, 0.12 \mathrm{mmol})$ in anhydrous DMF $(2.5 \mathrm{ml})$ were added the amine $9 \mathrm{a}^{4}(36 \mathrm{mg}$, $0.14 \mathrm{mmol}$ ), HATU (46 mg, $0.12 \mathrm{mmol}$ ) and $\mathrm{HOBt}(22 \mathrm{mg}, 0.14 \mathrm{mmol})$. The mixture was stirred under $\mathrm{N}_{2}$ for 15 min at room temperature 
before DIPEA ( $62 \mathrm{mg}, 0.48 \mathrm{mmol}$ ) was added drop wise. The mixture was stirred under $\mathrm{N}_{2}$ at room temperature for $21 \mathrm{~h}$ before acidified to $\mathrm{pH} 1$ with $1 \mathrm{M} \mathrm{HCl}$. The mixture was extracted with EtOAc $(3 \times 20 \mathrm{ml})$. The combined organic phase was washed with $1 \mathrm{M} \mathrm{HCl}(10$ $\mathrm{ml})$, sat. $\mathrm{NaHCO}_{3}(2 \times 15 \mathrm{ml}), \mathrm{H}_{2} \mathrm{O}(2 \times 15 \mathrm{ml})$ and brine $(20 \mathrm{ml})$ and dried over $\mathrm{Na}_{2} \mathrm{SO}_{4}$. The solvent was removed in vacuo and the resultant crude product was purified with rp-HPLC to give compound $\mathbf{1 a}$ as a yellow oil $(12 \mathrm{mg}, 15 \%) .{ }^{1} \mathrm{H} \mathrm{NMR}\left(300 \mathrm{MHz}, \mathrm{CDCl}{ }_{3}\right) \delta 7.36$ - 7.30 (m, 5H, Cbz ArH), $6.69-6.64$ (m, 1H, NH), 6.41 (br s, 1H, NH), $5.35-5.31$ (m, 1H, NH), 5.10 (br s, 2H, Cbz CHz), $4.36-4.27$ $\left(\mathrm{m}, 2 \mathrm{H}, \mathrm{CbzNHCHCO}\right.$ and $\left.\mathrm{NHCHCH}_{2} \mathrm{Ar}\right), 4.17-4.11\left(\mathrm{~m}, 1 \mathrm{H}, \mathrm{Ile} \mathbf{H}_{\boldsymbol{\alpha}}\right), 3.27-3.20\left(\mathrm{~m}, 3 \mathrm{H}, \mathrm{CH}_{2} \mathrm{~N}_{3}\right.$ and pinanediol CH), $2.39-2.30(\mathrm{~m}$, $1 \mathrm{H}$, pinanediol CHH), $2.23-2.15\left(\mathrm{~m}, 1 \mathrm{H}\right.$, pinanediol CH), $2.06-2.00\left(\mathrm{~m}, 1 \mathrm{H}\right.$, pinanediol CH), $1.94-1.79\left(\mathrm{~m}, 4 \mathrm{H}\right.$, Ile $\mathbf{H}_{\beta}, \mathrm{Leu} \mathbf{H}_{\gamma}$ and $\left.\mathrm{CH}_{2} \mathrm{CH}_{2} \mathrm{CH}_{2} \mathrm{CH}_{2} \mathrm{~N}_{3}\right), 1.69-1.54\left(\mathrm{~m}, 4 \mathrm{H}\right.$, pinanediol $\mathrm{CH}_{2}$ and $\left.\mathrm{CH}_{2} \mathrm{CH}_{2} \mathrm{CH}_{2} \mathrm{CH}_{2} \mathrm{~N}_{3}\right), 1.51-1.41\left(\mathrm{~m}, 6 \mathrm{H}, \mathrm{CH}_{2} \mathrm{CH}_{2} \mathrm{CH}_{2} \mathrm{CH}_{2} \mathrm{~N}_{3}, \mathrm{CH}_{2} \mathrm{CH}_{2} \mathrm{CH}_{3}\right)_{2}$ and $\left.\mathrm{CH}_{3} \mathrm{CHCH}_{2} \mathrm{CH}_{3}\right), 1.37\left(\mathrm{~s}, 3 \mathrm{H}\right.$, pinanediol $\left.\mathrm{CH}_{3}\right), 1.29\left(\mathrm{~s}, 3 \mathrm{H}\right.$, pinanediol $\left.\mathrm{CH}_{3}\right), 1.10-1.02(\mathrm{~m}, 1 \mathrm{H}$, pinanediol $\mathrm{CHH}), 0.96-0.83(\mathrm{~m}$, $15 \mathrm{H}, 2 \times \mathrm{Leu} \mathrm{CH}_{3}$, Ile $2 \times \mathrm{CH}_{3}$ and pinanediol $\left.\mathrm{CH}_{3}\right) .{ }^{13} \mathrm{C} \mathrm{NMR}\left(126 \mathrm{MHz}, \mathrm{CDCl}_{3}\right) \delta 171.4,156.2,136.0,128.6,128.3,128.1,67.3,56.9$, 55.1, 51.4, 51.0, 50.8, 39.9, 39.7, 39.6, 38.2, 37.0, 35.6, 32.0, 28.6, 28.4, 27.1, 26.3, 25.6, 25.5, 24.6, 24.0, 22.9, 22.6, 22.0, 15.3, 11.3. Analytical RP-HPLC: $\mathrm{t}_{\mathrm{R}}=24.2 \mathrm{~min}(\mathrm{~A} / \mathrm{B} 100: 0$ to $0: 100$ in $25 \mathrm{~min}, \lambda=220 \mathrm{~nm})$. HRMS (ES) $665.4198\left(\mathrm{M}_{-} \mathrm{H}^{-}\right) ; \mathrm{C}_{35} \mathrm{H}_{55} \mathrm{BN}_{6} \mathrm{O}_{6} \mathrm{requires}$ 665.4205 .

Boronic ester inhibitor $\mathbf{1 b}$ : To a solution of free acid $\mathbf{8}(65 \mathrm{mg}, 0.16 \mathrm{mmol})$ in anhydrous DMF $(3 \mathrm{ml})$ were added the amine $9 \mathbf{b}^{4}(63 \mathrm{mg}$, $0.19 \mathrm{mmol})$, HATU $(61 \mathrm{mg}, 0.16 \mathrm{mmol})$ and HOBt $(29 \mathrm{mg}, 0.19 \mathrm{mmol})$. The mixture was stirred under $\mathrm{N}_{2}$ for $15 \mathrm{~min}$ at room temperature before DIPEA ( $83 \mathrm{mg}, 0.64 \mathrm{mmol}$ ) was added drop wise. The mixture was stirred under $\mathrm{N}_{2}$ at room temperature for $21 \mathrm{~h}$ before acidified to $\mathrm{pH} 1$ with $1 \mathrm{M} \mathrm{HCl}$. The mixture was extracted with EtOAc $(3 \times 20 \mathrm{ml})$. The combined organic phase was washed with $1 \mathrm{M} \mathrm{HCl}(10$ $\mathrm{ml})$, sat. $\mathrm{NaHCO}_{3}(2 \times 15 \mathrm{ml}), \mathrm{H}_{2} \mathrm{O}(2 \times 15 \mathrm{ml})$ and brine $(20 \mathrm{ml})$ and dried over $\mathrm{Na}_{2} \mathrm{SO}_{4}$. The solvent was removed in vacuo and the resultant crude product was purified with rp-HPLC to give the crude product as a yellow oil (90 mg). The crude product was purified by RP-HPLC to give compound $\mathbf{1 b}$ as a yellow oil $(11 \mathrm{mg}, 10 \%) .{ }^{1} \mathrm{H}$ NMR $\left(300 \mathrm{MHz}, \mathrm{CDCl}_{3}\right) \delta 7.38-7.27(\mathrm{~m}, 7 \mathrm{H}, \mathrm{Cbz} \mathrm{ArH}$ and Phe ArH), $7.23-7.21(\mathrm{~m}, 3 \mathrm{H}, \mathrm{Cbz}$ ArH and Phe ArH), 6.50 (d, J=7.0 Hz, 1H, NH), 6.44 (br s, 1H, NH), 5.21 (br s, $1 \mathrm{H}, \mathrm{NH}), 5.05$ (br s, 2H, Cbz $\left.\mathrm{CH}_{2}\right), 4.33-4.27\left(\mathrm{~m}, 2 \mathrm{H}, \mathrm{CbzNHCHCO}\right.$ and $\left.\mathrm{NHCHCH}_{2} \mathrm{Ar}\right), 4.11-4.04\left(\mathrm{~m}, 1 \mathrm{H}\right.$, Ile $\left.\mathbf{H}_{\boldsymbol{a}}\right), 3.26-3.21\left(\mathrm{~m}, 3 \mathrm{H}, \mathrm{CH} \mathbf{H}_{3}\right.$ and pinanediol CH) $2.98(\mathrm{dd}, J=13.5,5.5 \mathrm{~Hz}, 1 \mathrm{H}, \mathrm{CHHAr}), 2.78(\mathrm{dd}, J=13.5,10 \mathrm{~Hz}, 1 \mathrm{H}, \mathrm{CHHAr}), 2.37-2.30$ (m, 1H, pinanediol CHH), $2.17-2.10$ (m, $1 \mathrm{H}$, pinanediol $\mathbf{C H}), 2.00(\mathrm{t}, J=5.5 \mathrm{~Hz}, 1 \mathrm{H}$, pinanediol $\mathrm{CH}), 1.91-1.76\left(\mathrm{~m}, 3 \mathrm{H}\right.$, Ile $\mathbf{H}_{\beta}$ and $\left.\mathrm{CH}_{2} \mathrm{CH}_{2} \mathrm{CH}_{2} \mathrm{CH}_{2} \mathrm{~N}_{3}\right), 1.64-1.52(\mathrm{~m}, 4 \mathrm{H}$, pinanediol $\mathrm{CH}_{2}$ and $\left.\mathrm{CH}_{2} \mathrm{CH}_{2} \mathrm{CH}_{2} \mathrm{CH}_{2} \mathrm{~N}_{3}\right), 1.45-1.33\left(\mathrm{~m}, 4 \mathrm{H}, \mathrm{CH}_{2} \mathrm{CH}_{2} \mathrm{CH}_{2} \mathrm{CH}_{2} \mathrm{~N}_{3}\right.$ and $\left.\mathrm{CH}_{3} \mathrm{CHCH}_{2} \mathrm{CH}_{3}\right)$, $1.36\left(\mathrm{~s}, 3 \mathrm{H}\right.$, pinanediol $\left.\mathrm{CH}_{3}\right)$, $1.27\left(\mathrm{~s}, 3 \mathrm{H}\right.$, pinanediol $\left.\mathrm{CH}_{3}\right), 1.06-0.99(\mathrm{~m}, 1 \mathrm{H}$, pinanediol $\mathrm{CHH}), 0.87-0.83\left(\mathrm{~m}, 9 \mathrm{H}, \mathrm{CH}_{3} \mathrm{CHCH}_{2} \mathrm{CH}_{3}\right.$ and pinanediol $\left.\mathrm{CH}_{3}\right) .{ }^{13} \mathrm{C} \mathrm{NMR}$ $\left(126 \mathrm{MHz}, \mathrm{CDCl}_{3}\right) \delta 171.3,156.2,139.5,135.9,129.0,128.6,128.3,128.2,126.4,85.7,67.3,56.3,55.0,51.6,51.0,39.7,38.1,37.0,35.8$, $31.7,28.6,28.4,27.1,26.3,24.6,24.1,22.6,15.2,11.3$. Analytical RP-HPLC: $\mathrm{t}_{\mathrm{R}}=23.5 \mathrm{~min}(\mathrm{~A} / \mathrm{B} 100: 0$ to $0: 100$ in $25 \mathrm{~min}, \lambda=220$ nm). HRMS (ES) $700.4108\left(\mathrm{MH}^{+}\right) ; \mathrm{C}_{38} \mathrm{H}_{53} \mathrm{BN}_{6} \mathrm{O}_{6}$ requires 700.4120 .

Boronic ester inhibitor $2 \boldsymbol{a}$ : To a solution of free acid $15(67 \mathrm{mg}, 0.12 \mathrm{mmol})$ in anhydrous DMF (2.5 ml) were added the amine $9 \mathrm{a}^{4}(36 \mathrm{mg}$, $0.14 \mathrm{mmol}$ ), HATU (46 mg, $0.12 \mathrm{mmol}$ ) and HOBt $(22 \mathrm{mg}, 0.14 \mathrm{mmol})$. The mixture was stirred under $\mathrm{N}_{2}$ for $15 \mathrm{~min}$ at room temperature before DIPEA (62 mg, $0.48 \mathrm{mmol}$ ) was added dropwise. The mixture was stirred under $\mathrm{N}_{2}$ at room temperature for $21 \mathrm{~h}$ before acidified to $\mathrm{pH} 1$ with $1 \mathrm{M} \mathrm{HCl}$. The mixture was extracted with EtOAc $(3 \times 20 \mathrm{ml})$. The combined organic phase was washed with $1 \mathrm{M} \mathrm{HCl}(10$ $\mathrm{ml})$, sat. $\mathrm{NaHCO}_{3}(2 \times 15 \mathrm{ml}), \mathrm{H}_{2} \mathrm{O}(2 \times 15 \mathrm{ml})$ and brine $(20 \mathrm{ml})$ and dried over $\mathrm{Na}_{2} \mathrm{SO}_{4}$. The solvent was removed in vacuo and the resultant crude product was purified with rp-HPLC to give compound $2 \mathrm{a}$ as a clear oil $(14 \mathrm{mg}, 16 \%) .{ }^{1} \mathrm{H} \mathrm{NMR}\left(500 \mathrm{MHz}, \mathrm{CDCl} \mathrm{N}_{3}\right) \delta 10.36$ (br s, 1H, pyrrole NH), $7.16(\mathrm{~d}, J=10.2 \mathrm{~Hz}, 2 \mathrm{H}, \mathrm{OArH}), 7.12(\mathrm{~d}, J=10.2 \mathrm{~Hz}, 2 \mathrm{H}, \mathrm{OArH}), 7.08-7.02(\mathrm{~m}, 2 \mathrm{H}, \mathrm{OArH}), 6.84(\mathrm{~d}, J=10.2$ $\mathrm{Hz}, 2 \mathrm{H}, \mathrm{OArH}), 6.83-6.78(\mathrm{~m}, 2 \mathrm{H}, 2 \times \mathrm{NH}), 6.57$ (br s, $1 \mathrm{H}$, pyrrole $\mathbf{H}), 6.29($ br s, $1 \mathrm{H}$, pyrrole $\mathbf{H}), 6.08-5.97\left(\mathrm{~m}, 2 \mathrm{H}, 2 \times \mathrm{OCH}_{2} \mathrm{CHCH}_{2}\right)$, $5.42-5.34\left(\mathrm{~m}, 2 \mathrm{H}, 2 \times \mathrm{OCH}_{2} \mathrm{CHCHH}\right), 5.29-5.24\left(\mathrm{~m}, 2 \mathrm{H}, 2 \times \mathrm{OCH}_{2} \mathrm{CHCHH}\right), 4.89-4.84\left(\mathrm{~m}, 1 \mathrm{H}, \mathrm{CHCH}_{2} \mathrm{ArO}\right), 4.52-4.44(\mathrm{~m}, 3 \mathrm{H}$, $\mathrm{OCH}_{2} \mathrm{CHCH}_{2}$ and $\left.\mathrm{NHCHB}\right), 4.29\left(\mathrm{~d}, J=12.0 \mathrm{~Hz}, 2 \mathrm{H}, \mathrm{OCH}_{2} \mathrm{CHCH}_{2}\right), 3.24-3.20(\mathrm{~m}, 1 \mathrm{H}$, pinanediol CH$), 3.19-3.05(\mathrm{~m}, 4 \mathrm{H}$, $\left.\mathrm{OCH}_{2} \mathrm{CH}_{2} \mathrm{Ar}\right), 3.00-2.90\left(\mathrm{~m}, 3 \mathrm{H}, \mathrm{C} \mathbf{H}_{2} \mathrm{Ar}\right.$ and $\left.\mathrm{CH}\left(\mathrm{CH}_{3}\right)_{2}\right), 2.36-2.30(\mathrm{~m}, 1 \mathrm{H}$, pinanediol CHH), $2.20-2.14(\mathrm{~m}, 1 \mathrm{H}$, pinanediol $\mathrm{CH})$, $2.02-2.00(\mathrm{~m}, 1 \mathrm{H}$, pinanediol $\mathbf{C H}), 1.84-1.72\left(\mathrm{~m}, 3 \mathrm{H}, \mathbf{C H}_{2} \mathrm{CH}\left(\mathrm{CH}_{3}\right)_{2}\right.$, pinaneldiol $\left.\mathrm{CHH}\right), 1.38(\mathrm{~s}, 3 \mathrm{H}$, pinanediol $\mathrm{CH}), 1.28(\mathrm{~s}, 3 \mathrm{H}$, pinanediol $\left.\mathrm{CH}_{3}\right), 1.47-1.23(\mathrm{~m}, 1 \mathrm{H}$, pinanediol $\mathrm{CHH}), 1.21-1.18(\mathrm{~m}, 1 \mathrm{H}$, pinanediol $\mathrm{CHH}), 0.90-0.75\left(\mathrm{~m}, 9 \mathrm{H}\right.$, pinanediol $\mathrm{CH}_{3}$ and $\left.\mathrm{CH}\left(\mathrm{CH}_{3}\right)_{2}\right) .{ }^{13} \mathrm{C}$ NMR $\left(126 \mathrm{MHz}, \mathrm{CDCl}_{3}\right) \delta 190.3,171.3,159.6,157.6,157.0,133.4,133.2,133.1,130.5,130.4,129.2,128.3,117.6,117.6$, 115.8, 114.8, 110.6, 77.8, 68.8, 68.7, 53.9, 51.3, 40.3, 39.9, 39.5, 38.2, 37.8, 35.5, 29.6, 28.5, 27.1, 27.0, 26.3, 25.3, 24.0, 22.9, 21.9. Analytical RP-HPLC: $\mathrm{t}_{\mathrm{R}}=23.6 \mathrm{~min}(\mathrm{~A} / \mathrm{B} 100: 0$ to $0: 100$ in $25 \mathrm{~min}, \lambda=220 \mathrm{~nm})$. HRMS (ES) $750.4203\left(\mathrm{MH}^{+}\right) ; \mathrm{C}_{44} \mathrm{H}_{56} \mathrm{BN}_{3} \mathrm{O}_{7} \mathrm{requires}$ 750.4211 .

Boronic ester inhibitor $\mathbf{2 b}$ : To a solution of free acid $15(53 \mathrm{mg}, 0.11 \mathrm{mmol})$ in anhydrous DMF $(2 \mathrm{ml})$ were added the amine $9 \mathbf{b}^{4}(33 \mathrm{mg}$, $0.13 \mathrm{mmol})$, HATU (42 $\mathrm{mg}, 0.11 \mathrm{mmol})$ and HOBt $(20 \mathrm{mg}, 0.13 \mathrm{mmol})$. The mixture was stirred under $\mathrm{N}_{2}$ for $15 \mathrm{~min}$ at room temperature before DIPEA ( $57 \mathrm{mg}, 0.44 \mathrm{mmol}$ ) was added dropwise. The mixture was stirred under $\mathrm{N}_{2}$ at room temperature for $21 \mathrm{~h}$ before acidified to $\mathrm{pH} 1$ with $1 \mathrm{M} \mathrm{HCl}$. The mixture was extracted with EtOAc $(3 \times 20 \mathrm{ml})$. The combined organic phase was washed with $1 \mathrm{M} \mathrm{HCl}(10$ $\mathrm{ml})$, sat. $\mathrm{NaHCO}_{3}(2 \times 15 \mathrm{ml}), \mathrm{H}_{2} \mathrm{O}(2 \times 15 \mathrm{ml})$ and brine $(20 \mathrm{ml})$ and dried over $\mathrm{Na}_{2} \mathrm{SO}_{4}$. The solvent was removed in vacuo and the resultant crude product was purified with rp-HPLC to give compound $\mathbf{2 b}$ as a clear oil $(15 \mathrm{mg}, 18 \%) .{ }^{1} \mathrm{H} \mathrm{NMR}\left(599 \mathrm{MHz}, \mathrm{CDCl}{ }_{3}\right) \delta 9.91$ (br s, 1H, pyrrole NH), $7.19-7.11(\mathrm{~m}, 7 \mathrm{H}, \mathrm{ArH}$ and OArH), $6.99(\mathrm{~d}, J=7.2 \mathrm{~Hz}, 2 \mathrm{H}, \mathrm{OArH}), 6.84(\mathrm{~d}, J=7.2 \mathrm{~Hz}, 2 \mathrm{H}, \mathrm{OArH}), 6.82(\mathrm{~d}, J$ $=7.2 \mathrm{~Hz}, 2 \mathrm{H}, \mathrm{OArH}), 6.78-6.74(\mathrm{~m}, 1 \mathrm{H}$, pyrrole $\mathbf{H}), 6.65(\mathrm{~d}, J=8.4 \mathrm{~Hz}, 1 \mathrm{H}, \mathrm{NHCHCO}), 6.48-6.45(\mathrm{~m}, 1 \mathrm{H}$, pyrrole H), $6.08-6.00(\mathrm{~m}$, $\left.2 \mathrm{H}, 2 \times \mathrm{OCH}_{2} \mathrm{CHCH}_{2}\right), 5.96($ br s, $1 \mathrm{H}, \mathrm{NHCHB}), 5.42-5.37\left(\mathrm{~m}, 2 \mathrm{H}, 2 \times \mathrm{OCH}_{2} \mathrm{CHCHH}_{2}, 5.29-5.25\left(\mathrm{~m}, 2 \mathrm{H}, 2 \times \mathrm{OCH}_{2} \mathrm{CHCHH}\right), 4.71\right.$ $\left(\mathrm{q}, J=7.8 \mathrm{~Hz}, 1 \mathrm{H}, \mathrm{CHCH}_{2} \mathrm{ArO}\right), 4.51-4.48\left(\mathrm{~m}, 3 \mathrm{H}, \mathrm{OCH}_{2} \mathrm{CHCH}_{2}\right.$ and $\left.\mathrm{CHCH}_{2} \mathrm{Ar}\right), 4.36-4.30\left(\mathrm{~m}, 2 \mathrm{H}, \mathrm{OCH}_{2} \mathrm{CHCH}_{2}\right), 3.28-3.25(\mathrm{~m}$, $1 \mathrm{H}$, pinanediol CH), $3.10-3.08\left(\mathrm{~m}, 2 \mathrm{H}, \mathrm{CH}_{2} \mathrm{Ar}\right), 3.01-2.90\left(\mathrm{~m}, 4 \mathrm{H}, \mathrm{OCH}_{2} \mathrm{CH}_{2} \mathrm{ArO}\right), 2.70-2.65(\mathrm{~m}, 2 \mathrm{H}, \mathrm{CH} 2 \mathrm{Ar}), 2.38-2.32(\mathrm{~m}, 1 \mathrm{H}$, pinanediol CHH), $2.18-2.13(\mathrm{~m}, 1 \mathrm{H}$, pinanediol $\mathrm{CH}), 2.01(\mathrm{t}, J=5.5 \mathrm{~Hz}, 1 \mathrm{H}$, pinanediol $\mathrm{CH}), 1.92-1.85(\mathrm{~m}, 2 \mathrm{H}$, pinanediol CH$), 1.38$ $\left(\mathrm{s}, 3 \mathrm{H}\right.$, pinanediol $\left.\mathrm{CH}_{3}\right), 1.28\left(\mathrm{~s}, 3 \mathrm{H}\right.$, pinanediol $\left.\mathrm{CH}_{3}\right), 1.15(\mathrm{~d}, J=10.8 \mathrm{~Hz}, 1 \mathrm{H}$, pinanediol $\mathrm{CHH}), 0.95\left(\mathrm{~s}, 3 \mathrm{H}\right.$, pinanediol $\left.\mathrm{CH}_{3}\right) .{ }^{13} \mathrm{C} \mathrm{NMR}$ 
$\left(151 \mathrm{MHz}, \mathrm{CDCl}_{3}\right) \delta 190.2,171.0,159.2,157.7,157.0,139.0,133.4,133.2,133.1,130.5,129.7,129.4,129.2,128.9,128.4,128.2,126.4$, $117.7,115.6,114.8,110.3,85.9,77.9,68.8,54.0,51.3,40.9,40.3,39.5,38.1,37.8,36.7,35.5,29.5,28.5,27.1$, 26.3, 24.0. Analytical RPHPLC: $\mathrm{t}_{\mathrm{R}}=24.2 \mathrm{~min}(\mathrm{~A} / \mathrm{B} 100: 0$ to $0: 100$ in $25 \mathrm{~min}, \lambda=220 \mathrm{~nm})$. HRMS (ES) $784.4130\left(\mathrm{MH}^{+}\right) ; \mathrm{C}_{47} \mathrm{H}_{54} \mathrm{BN}_{3} \mathrm{O}_{7}$ requires 784.4133 .

(S)-6-Azido-2-(benzyloxycarbonylamino)hexanoic acid 6: To a solution of Cbz-Lys-OH 5 (2.9 g, $10.27 \mathrm{mmol})$ in $\mathrm{ACN}(20 \mathrm{ml})$ and $\mathrm{H}_{2} \mathrm{O}$ $(10 \mathrm{ml})$ was added $\mathrm{Et}_{3} \mathrm{~N}(4.3 \mathrm{ml}, 30.81 \mathrm{mmol})$ and $\mathrm{CuSO}_{4} .5 \mathrm{H}_{2} \mathrm{O}(26 \mathrm{mg}, 0.10 \mathrm{mmol})$. The mixture was cooled in an ice bath while stirring for $30 \mathrm{~min}$. A solution of triflic azide $(2.7 \mathrm{~g}, 15.40 \mathrm{mmol})$ in ACN $(40 \mathrm{ml})$ was added slowly to this ice-cooled mixture. The mixture was further stirred for $30 \mathrm{~min}$ with ice cooling and was allowed to warmed up to room temperature over $18 \mathrm{~h}$. The volatiles were removed in vacuo. The mixture was diluted with $\mathrm{H}_{2} \mathrm{O}(75 \mathrm{ml})$ and washed with EtOAc $(3 \times 75 \mathrm{ml})$. The aqueous phase was cooled in an ice bath and acidified to $\mathrm{pH} 1$ with $2 \mathrm{M} \mathrm{HCl}$. The acidified aqueous phase was then extracted with EtOAc $(3 \times 75 \mathrm{ml})$. The combined organic phase was washed with brine $(100 \mathrm{ml})$ and dried over $\mathrm{MgSO}_{4}$. The solvent was removed in vacuo and the resultant crude product (3.1 g) was purified by flash chromatography (DCM:MeOH 99:1) to give compound 6 as a white solid $(907 \mathrm{mg}, 29 \%) .{ }^{1} \mathrm{H} \mathrm{NMR}(300 \mathrm{MHz} \mathrm{CDCl})_{3} \delta 7.44-$ $7.32(\mathrm{~m}, 5 \mathrm{H}, \mathrm{Cbz} \mathrm{ArH}), 5.28(\mathrm{~d}, J=8.2 \mathrm{~Hz}, 1 \mathrm{H}, \mathrm{NH}), 5.11\left(\mathrm{~s}, 2 \mathrm{H}, \mathrm{Cbz} \mathbf{C H}_{2}\right), 4.42\left(\mathrm{dd}, J=13.3,7.9 \mathrm{~Hz}, 1 \mathrm{H}, \mathbf{H}_{\boldsymbol{\alpha}}\right), 3.28(\mathrm{t}, J=6.6 \mathrm{~Hz}, 2 \mathrm{H}$, $\left.\mathrm{CH}_{2} \mathrm{~N}_{3}\right), 2.02-1.87\left(\mathrm{~m}, 2 \mathrm{H}, \mathrm{CH}_{2} \mathrm{CH}_{2} \mathrm{CH}_{2} \mathrm{CH}_{2} \mathrm{~N}_{3}\right), 1.68-1.38\left(\mathrm{~m}, 4 \mathrm{H},\left(\mathrm{CH}_{2}\right)_{2} \mathrm{CH}_{2} \mathrm{~N}_{3}\right)$.

(2S,3S)-Methyl 2-((S)-6-azido-2-(benzyloxycarbonylamino)hexanamido)-3-methylpentanoate 7: Isoleucine-OMe (500 mg, $3.44 \mathrm{mmol}) \mathrm{was}$ dissolved in anhydrous DCM (10 ml). Compound 6, EDCI $(328 \mathrm{mg}, 2.12 \mathrm{mmol})$, HOBt (329 mg, $2.44 \mathrm{mmol})$ and DIPEA (1.13 ml, 6.51 mmol) were added under $\mathrm{N}_{2}$. The mixture was stirred for $18 \mathrm{~h}$ at room temperature under $\mathrm{N}_{2}$ and quenched with $1 \mathrm{M} \mathrm{HCl}(10 \mathrm{ml})$. The mixture was diluted with DCM $(50 \mathrm{ml})$ and the organic phase was separate and washed with $1 \mathrm{M} \mathrm{HCl}(20 \mathrm{ml}), \mathrm{H}_{2} \mathrm{O}(2 \times 20 \mathrm{ml})$ and brine $(40 \mathrm{ml})$ and dried over $\mathrm{MgSO}_{4}$. The solvent was removed in vacuo to give a clear oil $(466 \mathrm{mg})$. The crude product was purified by flash chromatograhy (DCM:MeOH 99.5:0.5) to give compound 7 as a clear oil $(460 \mathrm{mg}, 36 \%) .{ }^{1} \mathrm{H} \mathrm{NMR}\left(300 \mathrm{MHz}, \mathrm{CDCl}_{3}\right) \delta 7.42-7.29(\mathrm{~m}$, $5 \mathrm{H}, \mathrm{Cbz}$ ArH $), 6.47(\mathrm{~d}, J=8.4 \mathrm{~Hz}, 1 \mathrm{H}, \mathrm{NH}), 5.36(\mathrm{~d}, J=7.3 \mathrm{~Hz}, 1 \mathrm{H}, \mathrm{NH}), 5.12\left(\mathrm{~s}, 2 \mathrm{H}, \mathrm{Cbz} \mathbf{C H}_{2}\right), 4.57\left(\mathrm{dd}, J=8.4,4.8 \mathrm{~Hz}, 1 \mathrm{H}, \mathbf{H}_{\boldsymbol{a}}\right), 4.20$ $\left(\mathrm{q}, J=7.3 \mathrm{~Hz}, 1 \mathrm{H}, \mathbf{H}_{\boldsymbol{\alpha}}\right), 3.74(\mathrm{~s}, 3 \mathrm{H}, \mathrm{OCH}), 3.26\left(\mathrm{t}, J=6.7 \mathrm{~Hz}, 2 \mathrm{H}, \mathrm{CH}_{2} \mathrm{~N}_{3}\right), 1.97-1.79\left(\mathrm{~m}, 2 \mathrm{H}, \mathrm{CH}_{2} \mathrm{CH}_{2} \mathrm{CH}_{2} \mathrm{CH}_{2} \mathrm{~N}_{3}\right), 1.74-1.54(\mathrm{~m}, 3 \mathrm{H}$, Ile $\mathbf{H}_{\beta}$ and $\left.\mathrm{CH}_{2} \mathrm{CH}_{2} \mathrm{CH}_{2} \mathrm{CH}_{2} \mathrm{~N}_{3}\right), 1.51-1.32\left(\mathrm{~m}, 3 \mathrm{H} \mathrm{CH}_{2} \mathrm{CH}_{2} \mathrm{CH}_{2} \mathrm{CH}_{2} \mathrm{~N}_{3}\right.$ and $\left.\mathrm{CH}_{3} \mathrm{CHCHHCH}_{3}\right), 1.22-1.06\left(\mathrm{~m}, 1 \mathrm{H}, \mathrm{CH}_{3} \mathrm{CHCHHCH}_{3}\right)$, $0.97-0.81\left(\mathrm{~m}, 6 \mathrm{H}, 2 \times\right.$ Ile $\left.\mathrm{CH}_{3}\right)$.

(2S,3S)-2-((S)-6-Azido-2-(benzyloxycarbonylamino)hexanamido)-3-methylpentanoic acid 8: To an ice-cooled solution of 7 (437 mg, 1.01 $\mathrm{mmol})$ in THF $(9 \mathrm{ml})$ was added $1 \mathrm{M} \mathrm{LiOH}(120 \mathrm{mg}, 5.05 \mathrm{mmol})$ slowly. The mixture was stirred for $16 \mathrm{~h}$ at room temperature and diluted with EtOAc $(12 \mathrm{ml})$. The mixture was acidified with $2 \mathrm{M} \mathrm{HCl}$ to $\mathrm{pH} 7$. The aqueous phase was separated and extracted with EtOAc $(2 \times$ $12 \mathrm{ml})$. The combined organic layer was washed wih brine $(20 \mathrm{ml})$ and dried over $\mathrm{MgSO}_{4}$. The solvent was removed in vacuo to give compound 8 as a pale yellow solid $(395 \mathrm{mg}, 93 \%)$. ${ }^{1} \mathrm{H}$ NMR $\left(300 \mathrm{MHz}, \mathrm{CDCl}_{3}\right) \delta 7.43-7.29(\mathrm{~m}, 5 \mathrm{H}, \mathrm{Cbz} \mathrm{ArH}), 6.66(\mathrm{~d}, J=8.5 \mathrm{~Hz}, 1 \mathrm{H}$, $\mathrm{NH}), 5.50(\mathrm{~d}, J=8.3 \mathrm{~Hz}, 1 \mathrm{H}, \mathrm{NH}), 5.12\left(\mathrm{~s}, 2 \mathrm{H}, \mathrm{Cbz} \mathbf{C H}_{2}\right), 4.58\left(\mathrm{dd}, J=8.3,4.7 \mathrm{~Hz}, 1 \mathrm{H}, \mathbf{H}_{\boldsymbol{\alpha}}\right), 4.32-4.17\left(\mathrm{~m}, 1 \mathrm{H}, \mathbf{H}_{\boldsymbol{\alpha}}\right), 3.25(\mathrm{t}, J=6.7 \mathrm{~Hz}$, $\left.2 \mathrm{H}, \mathrm{CH}_{2} \mathrm{~N}_{3}\right), 2.00-1.76\left(\mathrm{~m}, 2 \mathrm{H}, \mathrm{CH}_{2} \mathrm{CH}_{2} \mathrm{CH}_{2} \mathrm{CH}_{2} \mathrm{~N}_{3}\right), 1.74-1.52\left(\mathrm{~m}, 3 \mathrm{H}\right.$, Ile $\mathbf{H}_{\beta}$ and $\left.\mathrm{CH}_{2} \mathrm{CH}_{2} \mathrm{CH}_{2} \mathrm{CH}_{2} \mathrm{~N}_{3}\right), 1.52-1.34(\mathrm{~m}, 3 \mathrm{H}$, $\mathrm{CH}_{2} \mathrm{CH}_{2} \mathrm{CH}_{2} \mathrm{CH}_{2} \mathrm{~N}_{3}$ and $\left.\mathrm{CH}_{3} \mathrm{CHCHHCH}_{3}\right), 1.30-1.08\left(\mathrm{~m}, 1 \mathrm{H}, \mathrm{CH}_{3} \mathrm{CHCHHCH}_{3}\right), 0.92\left(\mathrm{~m}, 6 \mathrm{H}, 2 \times \mathrm{Ile} \mathrm{CH}_{3}\right)$.

Ethyl 5-(3-(4-(allyloxy)phenyl)propanoyl)-1H-pyrrole-2-carboxylate 12: To a solution of 10 (2.3 g, $10.00 \mathrm{mmol})$ in nitromethane (27 ml) was added $11(700 \mathrm{mg}, 5.00 \mathrm{mmol})$ and $\mathrm{Yb}(\mathrm{OTf})_{3}(310 \mathrm{mg}, 0.50 \mathrm{mmol})$. The dark red mixture was stirred at $45^{\circ} \mathrm{C}$ for $48 \mathrm{~h}$. The reaction was quenched by addition of sat. $\mathrm{NaHCO}_{3}(250 \mathrm{ml})$. The mixture was extracted with $\mathrm{Et}_{2} \mathrm{O}(3 \times 250 \mathrm{ml})$. The combined organic phase was washed with sat. $\mathrm{NaHCO}_{3}(250 \mathrm{ml}), \mathrm{H}_{2} \mathrm{O}(2 \times 200 \mathrm{ml})$ and brine $(250 \mathrm{ml})$ and dried over $\mathrm{MgSO}_{4}$. The solvent was removed in vacuo and the resultant brown oil was purified by flash chromatography $\left(\mathrm{Et}_{2} \mathrm{O} /\right.$ hexane $\left.2: 3\right)$ to give compound 12 as a yellow solid $(48 \mathrm{mg}, 32 \%) .{ }^{1} \mathrm{H}$ $\operatorname{NMR}\left(300 \mathrm{MHz}, \mathrm{CDCl}_{3}\right) \delta 9.81$ (br s, $1 \mathrm{H}$, pyrrole $\left.\mathbf{H}\right), 7.13(\mathrm{~d}, J=8.6 \mathrm{~Hz}, 2 \mathrm{H}, \mathrm{OArH}), 6.89-6.79(\mathrm{~m}, 4 \mathrm{H}, \mathrm{OArH}$ and pyrrole $\mathbf{H}), 6.12-$ $5.98\left(\mathrm{~m}, 1 \mathrm{H}, \mathrm{OCH}_{2} \mathrm{CHCH}_{2}\right), 5.44-5.36\left(\mathrm{~m}, 1 \mathrm{H}, \mathrm{OCH}_{2} \mathrm{CHCHH}\right), 5.31-5.25\left(\mathrm{~m}, 1 \mathrm{H}, \mathrm{OCH}_{2} \mathrm{CHCHH}\right), 4.53-4.49\left(\mathrm{~m}, 2 \mathrm{H}, \mathrm{OCH}_{2} \mathrm{CHCH}_{2}\right)$, $4.36\left(\mathrm{q}, J=7.1 \mathrm{~Hz}, 2 \mathrm{H}, \mathrm{OCH}_{2} \mathrm{CH}_{3}\right), 3.13-3.06\left(\mathrm{~m}, 2 \mathrm{H}, \mathrm{ArCH}_{2} \mathrm{CH}_{2}\right), 3.02-2.97\left(\mathrm{~m}, 2 \mathrm{H}, \mathrm{ArCH}_{2} \mathrm{CH}_{2}\right), 1.37\left(\mathrm{t}, J=7.1 \mathrm{~Hz}, 3 \mathrm{H}, \mathrm{OCH}_{2} \mathrm{CH}_{3}\right)$.

5-(3-(4-(Allyloxy)phenyl)propanoyl)-1 H-pyrrole-2-carboxylic acid 13: To a solution of 12 (740 mg, $2.26 \mathrm{mmol}) \mathrm{in} \mathrm{THF} / \mathrm{H}_{2} \mathrm{O}(1: 1,14.8 \mathrm{ml})$ was added $\mathrm{KOH}(1010 \mathrm{mg}, 18.10 \mathrm{mmol})$ in one portion and stirred at $40-50{ }^{\circ} \mathrm{C}$ for $18 \mathrm{~h}$. The reaction mixture was cooled in an ice bath and partitioned between water $(50 \mathrm{ml})$ and $\mathrm{Et}_{2} \mathrm{O}(50 \mathrm{ml})$. The ice-cooled aqueous phase was acidified to $\mathrm{pH} 1 \mathrm{with} \mathrm{HCl}(32 \%)$. The precipitate was washed with ice-cold water and the volatiles were removed in vacuo overnight to give compound $\mathbf{1 3}$ as a pale yellow solid (578 mg, 85\%). ${ }^{1} \mathrm{H}$ NMR $\left(300 \mathrm{MHz}, \mathrm{CDCl}_{3}\right) \delta 10.82$ (br s, $1 \mathrm{H}$, pyrrole NH), $7.14(\mathrm{~d}, J=8.5 \mathrm{~Hz}, 2 \mathrm{H}, \mathrm{OArH}), 7.02-6.98$ (m, $1 \mathrm{H}$, pyrrole H), $6.92-6.89\left(\mathrm{~m}, 1 \mathrm{H}\right.$, pyrrole H), $6.85(\mathrm{~d}, J=8.5 \mathrm{~Hz}, 2 \mathrm{H}, \mathrm{OArH}), 6.13-5.97\left(\mathrm{~m}, 1 \mathrm{H}, \mathrm{OCH}_{2} \mathrm{CHCH}_{2}\right), 5.40(\mathrm{~d}, J=17.3,1 \mathrm{H}$, $\left.\mathrm{OCH}_{2} \mathrm{CHCHH}\right), 5.28$ (d, $\left.J=10.5 \mathrm{~Hz}, 1 \mathrm{H}, \mathrm{OCH}_{2} \mathrm{CHCHH}\right), 4.51\left(\mathrm{~d}, J=5.3 \mathrm{~Hz}, 2 \mathrm{H}, \mathrm{OCH}_{2} \mathrm{CHCH}_{2}\right), 3.16\left(\mathrm{t}, J=7.0 \mathrm{~Hz}, 2 \mathrm{H}, \mathrm{ArCH} \mathrm{CH}_{2}\right)$, $3.01\left(\mathrm{t}, J=7.0 \mathrm{~Hz}, 2 \mathrm{H}, \mathrm{ArCH}_{2} \mathrm{CH}_{2}\right)$, COOH was not observed.

(S)-Methyl 2-(5-(3-(4-(allyloxy)phenyl)propanoyl)-1H-pyrrole-2-carboxamido)-3-(4-(allyloxy)phenyl)propanoate 14: To a solution of compound $13(272 \mathrm{mg}, 0.90 \mathrm{mmol})$ in anhydrous DMF $(20 \mathrm{ml})$ was added Tyr(All)-OMe (246 mg, $1.08 \mathrm{mmol}), \mathrm{HATU}$ (342 mg, 0.9 $\mathrm{mmol})$, HOBt (165 mg, $1.08 \mathrm{mmol})$ and DIPEA $(446 \mathrm{mg}, 3.6 \mathrm{mmol})$. The mixture was stirred under $\mathrm{N}_{2}$ at room temperature for $21 \mathrm{~h}$ before acidified to $\mathrm{pH} 1$ with $1 \mathrm{M} \mathrm{HCl}$. The mixture was extracted with EtOAc $(3 \times 150 \mathrm{ml})$. The combined organic phase was washed with $1 \mathrm{M}$ $\mathrm{HCl}(100 \mathrm{ml})$, sat. $\mathrm{NaHCO}_{3}(2 \times 150 \mathrm{ml}), \mathrm{H}_{2} \mathrm{O}(2 \times 150 \mathrm{ml})$ and brine $(200 \mathrm{ml})$ and dried over $\mathrm{Na}_{2} \mathrm{SO}_{4}$. The solvent was removed in vacuo and the resultant crude product was purified with flash chromatography (petroleum ether:EtOAc 2:1) to give compound $\mathbf{1 4}$ as a yellow oil (500 mg, 78\%). ${ }^{1} \mathrm{H}$ NMR (300 MHz, $\left.\mathrm{CDCl}_{3}\right) \delta 9.93$ (br s, 1H, pyrrole NH), 7.13 (d, J=8.6 Hz, 2H, OArH), $7.00(\mathrm{~d}, J=8.6 \mathrm{~Hz}, 2 \mathrm{H}$, OArH), $6.85(\mathrm{~d}, \mathrm{~J}=8.6 \mathrm{~Hz}, 2 \mathrm{H}, \mathrm{OArH}), 6.82(\mathrm{~d}, J=8.6 \mathrm{~Hz}, 2 \mathrm{H}, \mathrm{OArH}), 6.80-6.77$ (m, 1H, pyrrole $\mathbf{H}), 6.47-6.60$ (m, $2 \mathrm{H}, \mathrm{pyrrole} \mathbf{H}$ and $\mathrm{NHCH}), 6.11-5.97\left(\mathrm{~m}, 2 \mathrm{H}, 2 \times \mathrm{OCH}_{2} \mathrm{CHCH}_{2}\right), 5.44-5.35\left(\mathrm{~m}, 2 \mathrm{H}, 2 \times \mathrm{OCH}_{2} \mathrm{CHCHH}\right), 5.31-5.24\left(\mathrm{~m}, 2 \mathrm{H}, 2 \times \mathrm{OCH}_{2} \mathrm{CHCHH}\right)$, 
$5.00(\mathrm{dt}, J=7.7,5.5 \mathrm{~Hz}, 1 \mathrm{H}, \mathrm{NHCH}), 4.53-4.47\left(\mathrm{~m}, 4 \mathrm{H}, 2 \times \mathrm{OCH}_{2} \mathrm{CHCH}_{2}\right), 3.76\left(\mathrm{~s}, 3 \mathrm{H}, \mathrm{OCH}_{3}\right), 3.16-3.13\left(\mathrm{~m}, 2 \mathrm{H}, \mathrm{ArCH}_{2} \mathrm{CH}_{2} \mathrm{O}\right), 3.11$ - $3.04\left(\mathrm{~m}, 2 \mathrm{H}, \mathrm{ArCH}_{2} \mathrm{CH}_{2}\right), 3.01-2.94\left(\mathrm{~m}, 2 \mathrm{H}, \mathrm{ArCH}_{2} \mathrm{CH}\right)$.

(S)-3-(4-(allyloxy)phenyl)-2-(5-(3-(4-(allyloxy)phenyl)propanoyl)-1H-pyrrole-2-carboxamido)propanoic acid 15: To a solution of compound $14(271 \mathrm{mg}, 0.54 \mathrm{mmol})$ in $\mathrm{THF} / \mathrm{H}_{2} \mathrm{O}(1: 1,5 \mathrm{ml})$ was added $\mathrm{NaOH}(173 \mathrm{mg}, 4.32 \mathrm{mmol})$. The mixture was stirred at room temperature for $18 \mathrm{~h}$. THF was removed in vacuo. The solution was diluted with $\mathrm{H}_{2} \mathrm{O}(2 \mathrm{ml})$ and washed with $\mathrm{Et}_{2} \mathrm{O}(2 \mathrm{ml})$. The aqueous layer was neutralized to $\mathrm{pH} 7$ by $\mathrm{HCl}(32 \%)$ and concentrated in vacuo to give carboxylic acid 15 (286 mg, quant). ${ }^{1} \mathrm{H} \mathrm{NMR} \mathrm{(500} \mathrm{MHz,}$ $\left.\mathrm{CDCl}_{3}\right) \delta 7.12(\mathrm{~d}, J=4.2 \mathrm{~Hz}, 2 \mathrm{H}, \mathrm{OArH}), 7.09(\mathrm{~d}, J=4.2 \mathrm{~Hz}, 2 \mathrm{H}, \mathrm{OArH}), 7.00(\mathrm{~d}, 1 \mathrm{H}$, pyrrole H), $6.90(\mathrm{~d}, J=4.5 \mathrm{~Hz}, 1 \mathrm{H}, \mathrm{NH}), 6.81-$ $6.74(\mathrm{~m}, 5 \mathrm{H}, 2 \times \mathrm{OArH}$ and pyrrole $\mathbf{H}), 6.07-5.93\left(\mathrm{~m}, 2 \mathrm{H}, 2 \times \mathrm{OCH}_{2} \mathrm{CHCH}_{2}\right), 5.39-5.28\left(\mathrm{~m}, 2 \mathrm{H}, 2 \times \mathrm{OCH}_{2} \mathrm{CHCHH}\right), 5.22-5.15(\mathrm{~m}$, $\left.2 \mathrm{H}, 2 \times \mathrm{OCH}_{2} \mathrm{CHCHH}\right), 4.70\left(\mathrm{dd}, J=4.8,8.1 \mathrm{~Hz}, 1 \mathrm{H}, \mathrm{CHCH}_{2} \mathrm{ArO}\right), 4.49-4.42\left(\mathrm{~m}, 4 \mathrm{H}, 2 \times \mathrm{OCH}_{2} \mathrm{CHCH}_{2}\right), 3.10-2.99(\mathrm{~m}, 4 \mathrm{H}$, $\left.\mathrm{OCH}_{2} \mathrm{CH}_{2} \mathrm{Ar}\right), 2.95-2.85$ (m, 2H, $\left.\mathrm{CH}_{2} \mathrm{Ar}\right)$

\section{h. ${ }^{1} \mathrm{H}$ and ${ }^{13} \mathrm{C}$ NMR Spectra:}

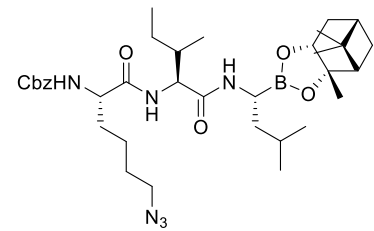

Compound 1a

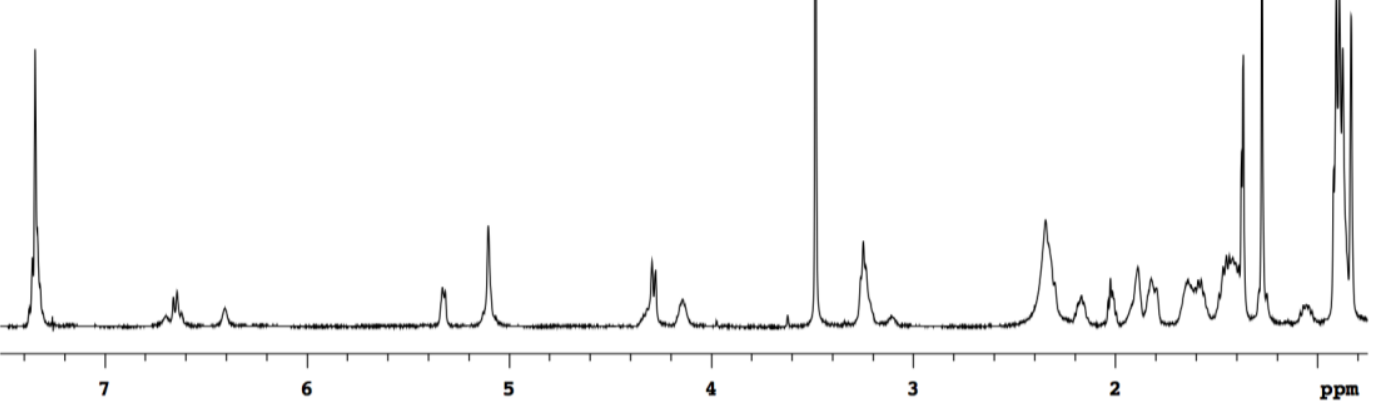

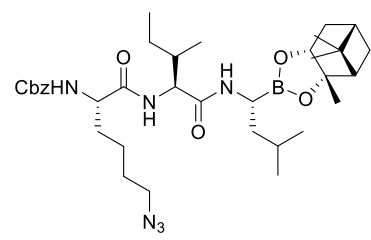

Compound 1a 

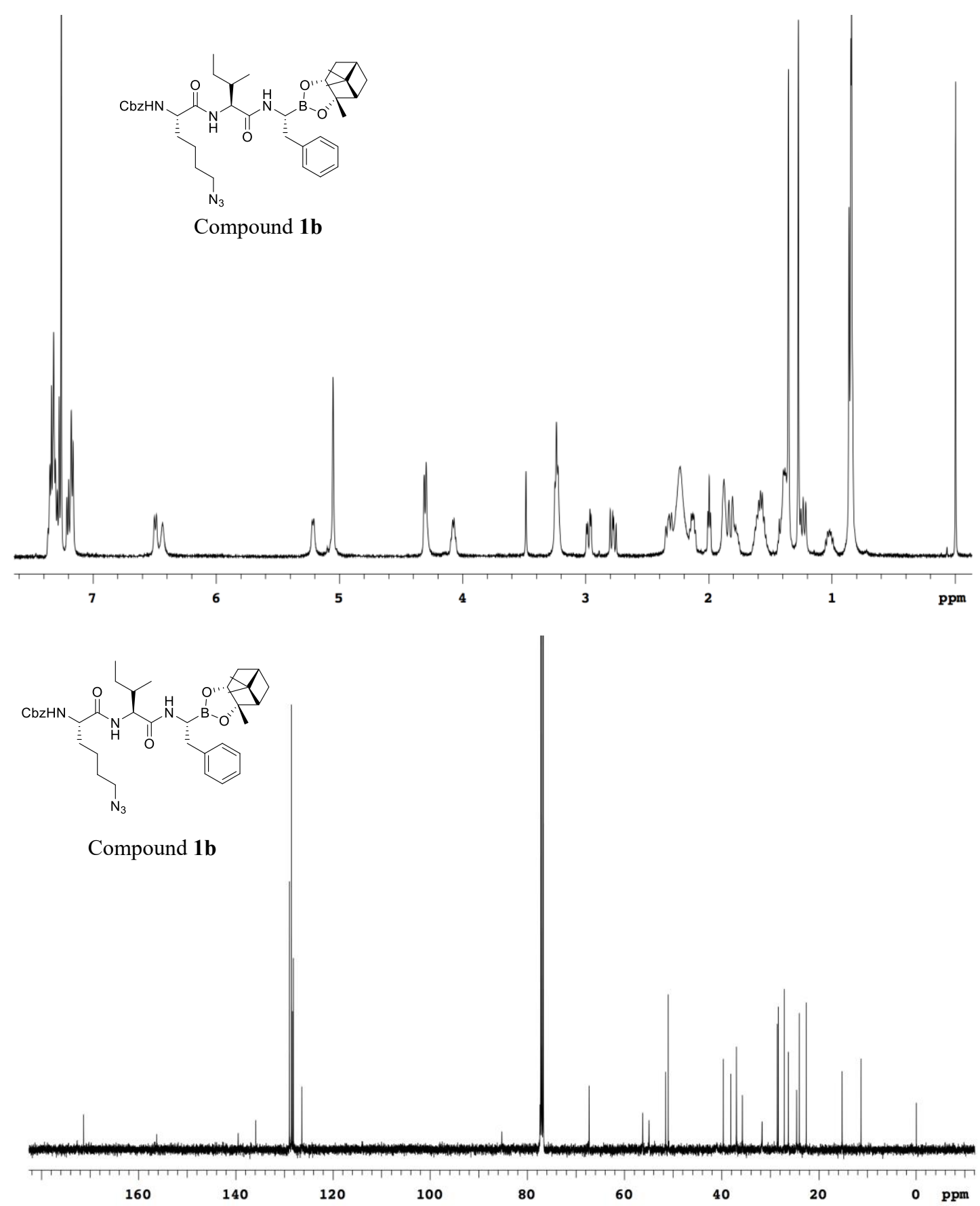

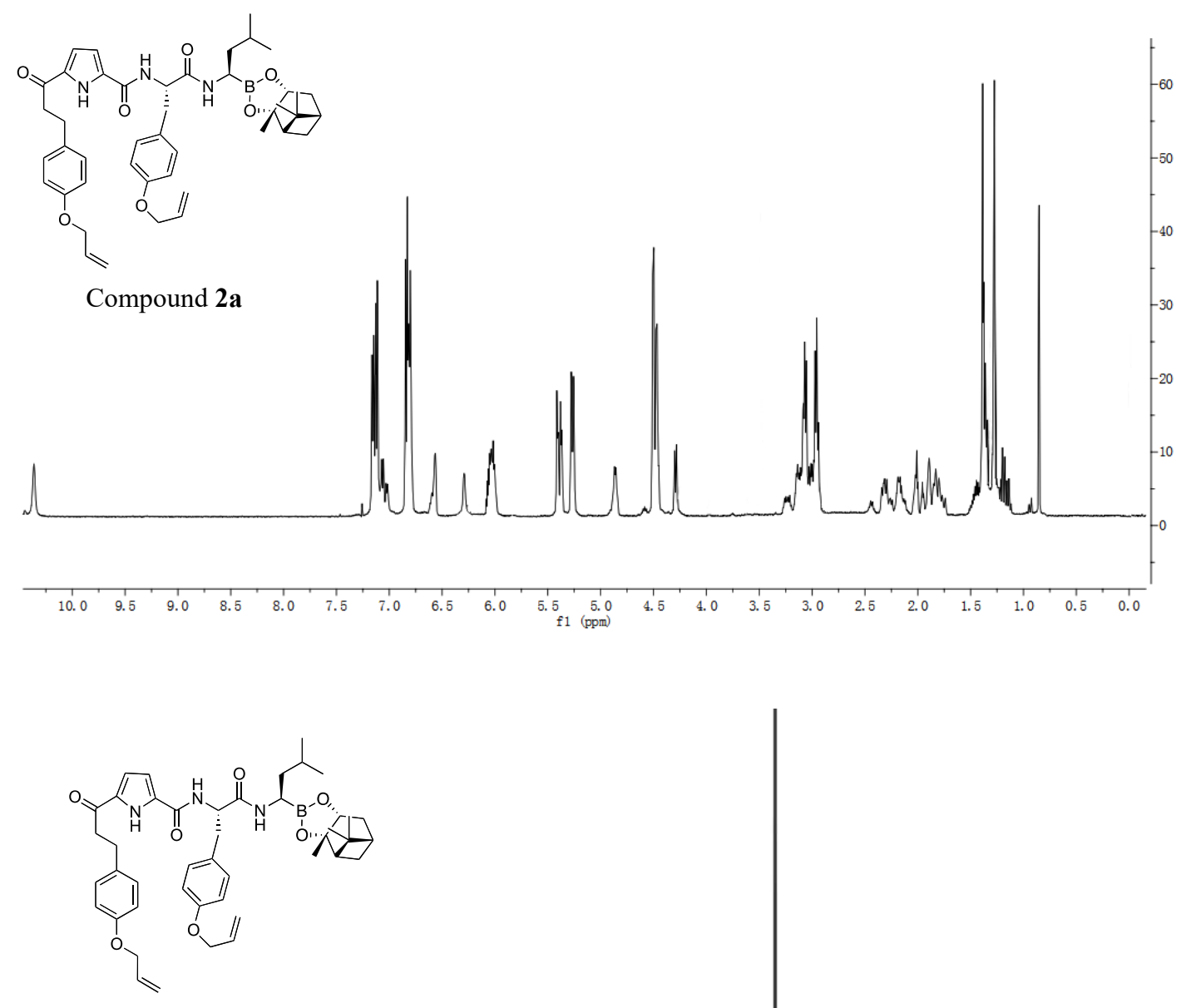

Compound 2a

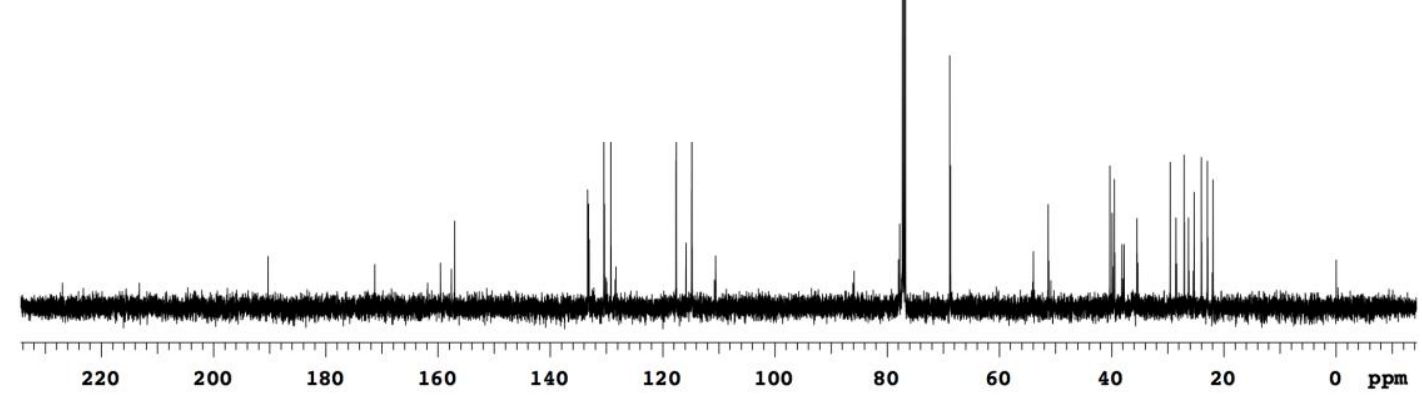



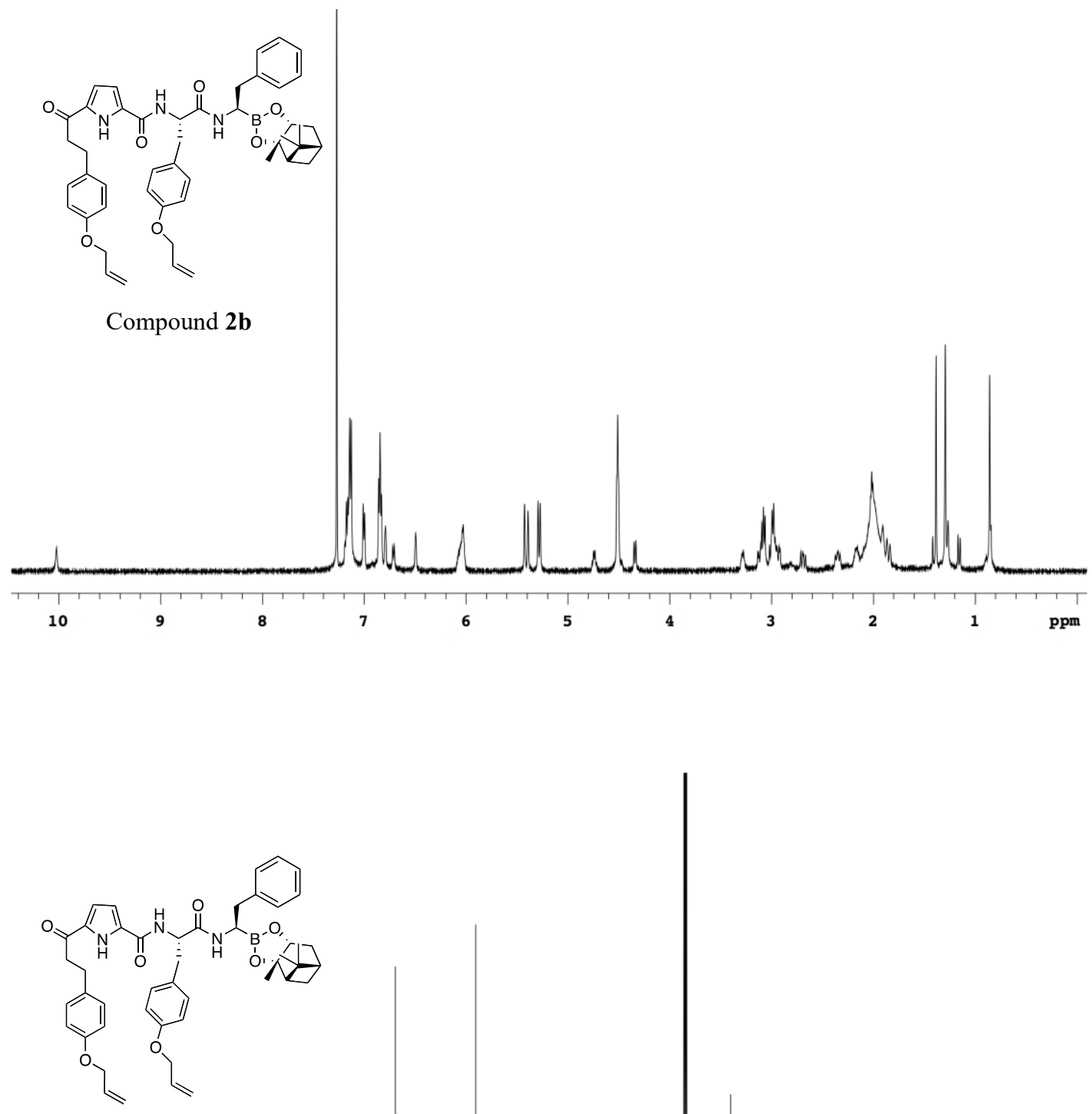

Compound 2b

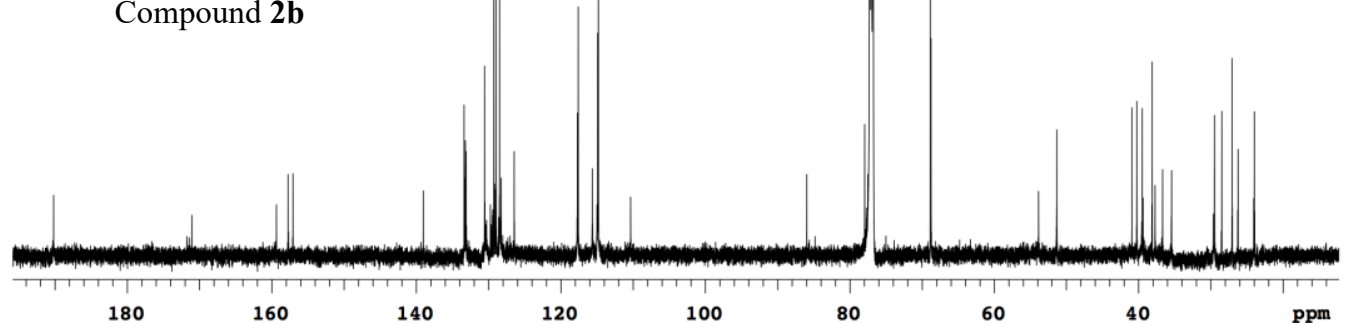




\section{i. HPLC Traces for Compounds 1a,b and 2a,b}

Compound 1a

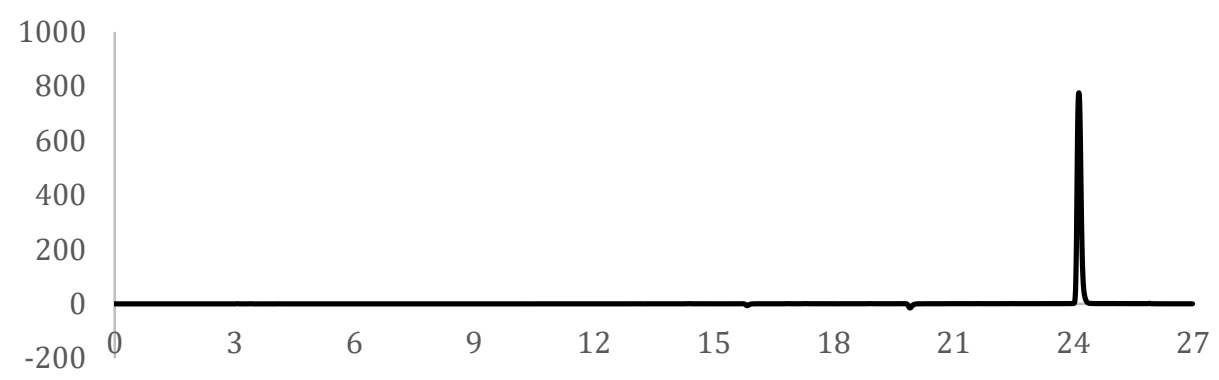

Compound $\mathbf{1 b}$

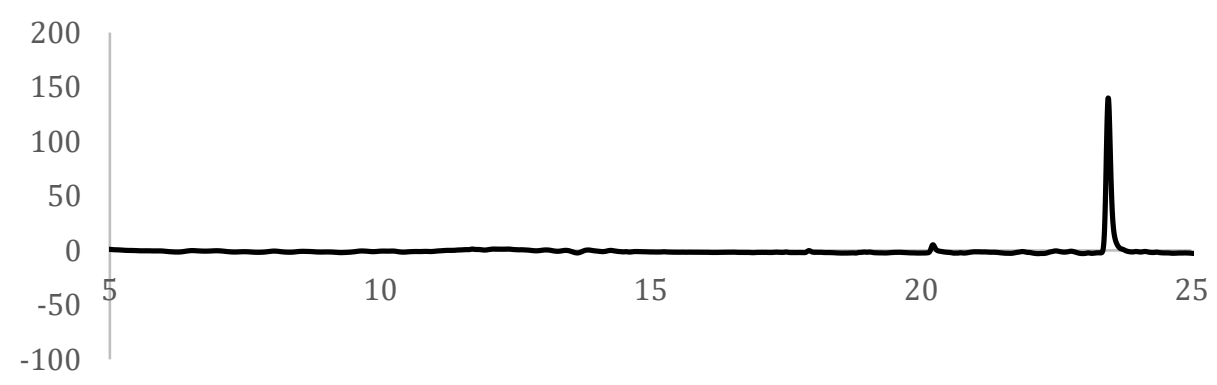

Compound 2a

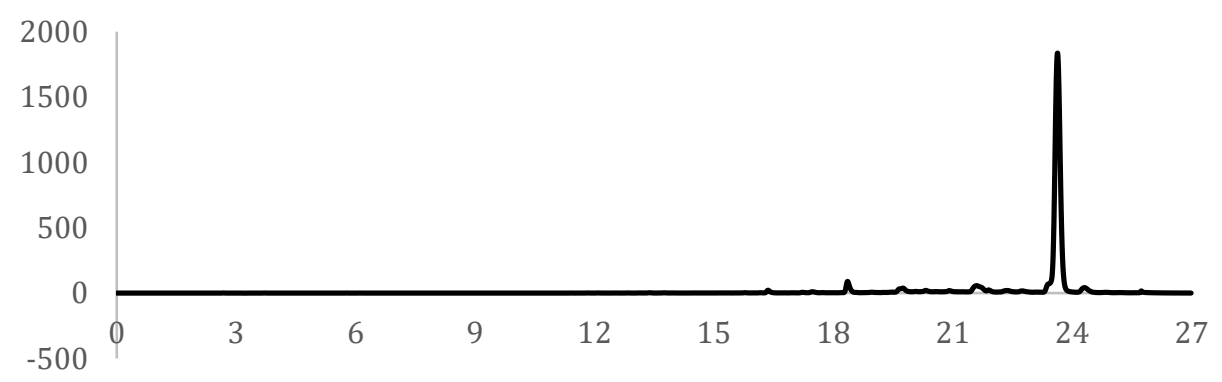

Compound 2b

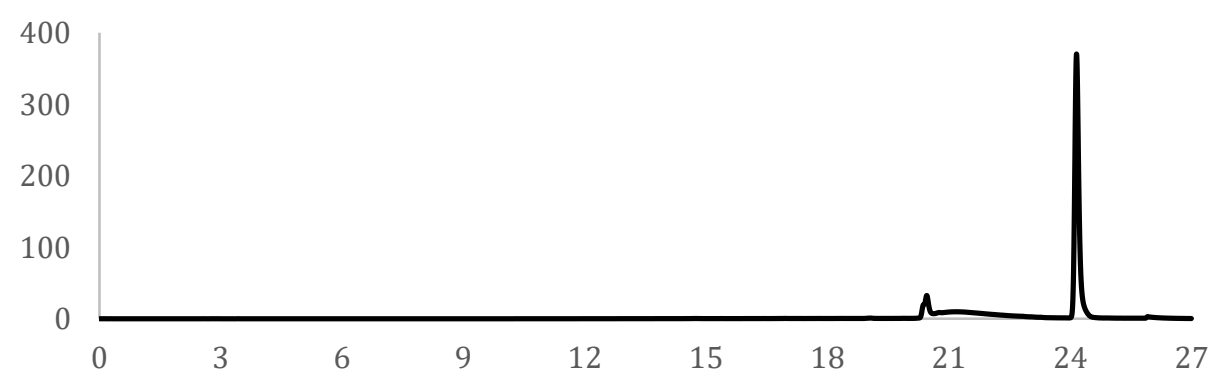




\section{j. Dose-response Curves for the Inhibition of $20 \mathrm{~S}$ proteasome}

Supplementary Figure S1: Dose response curves- Compound 1a

C T- L

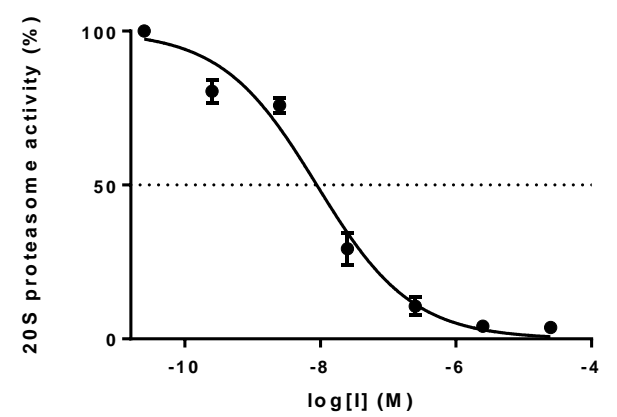

L M P 7

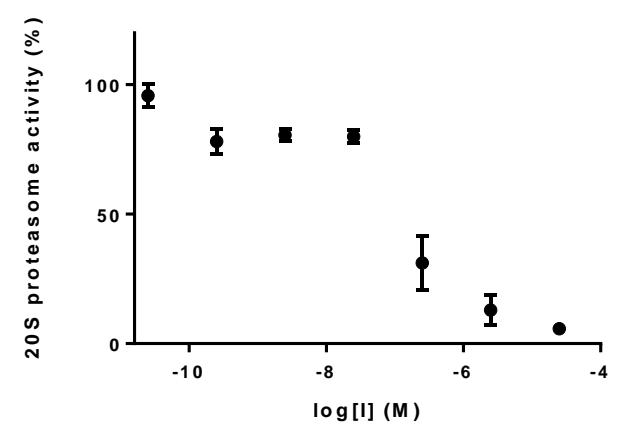

C - L

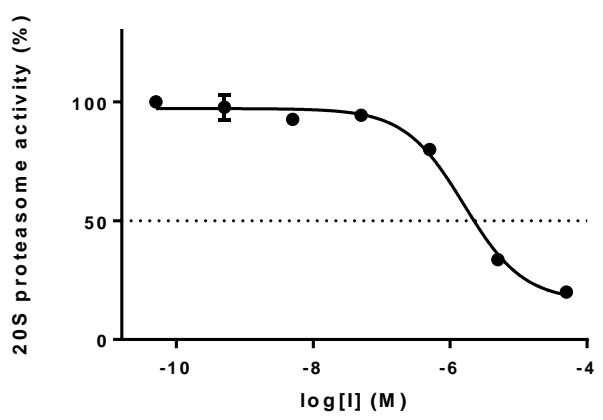

Supplementary Figure S1: Dose response curves- Compound 1b

C T - L

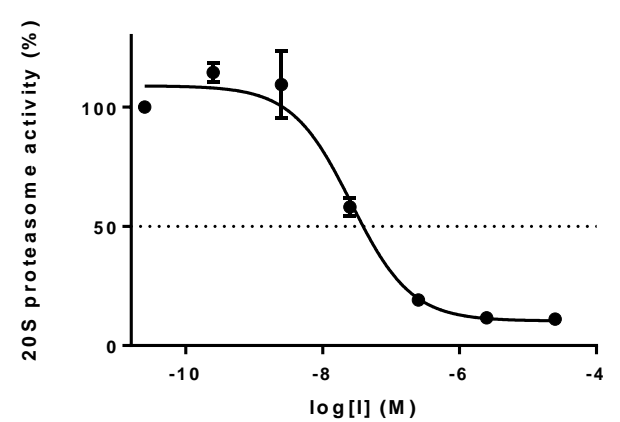

L M P 7

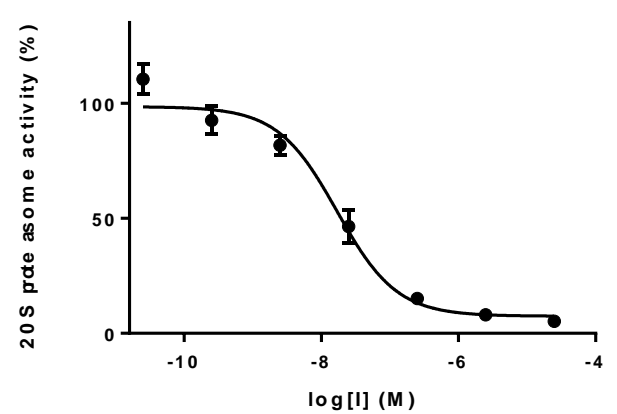

C-L

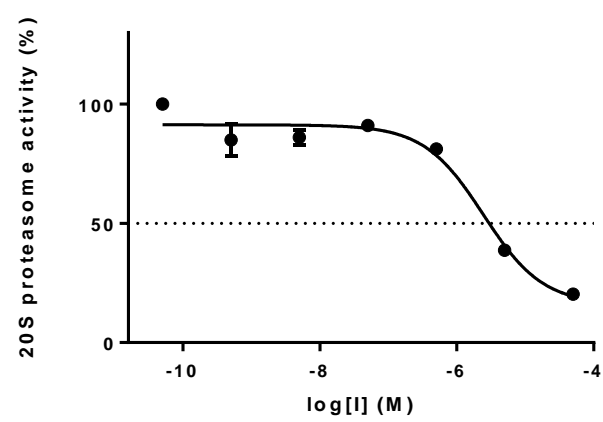


Supplementary Figure S1: Dose response curves- Compound 2a
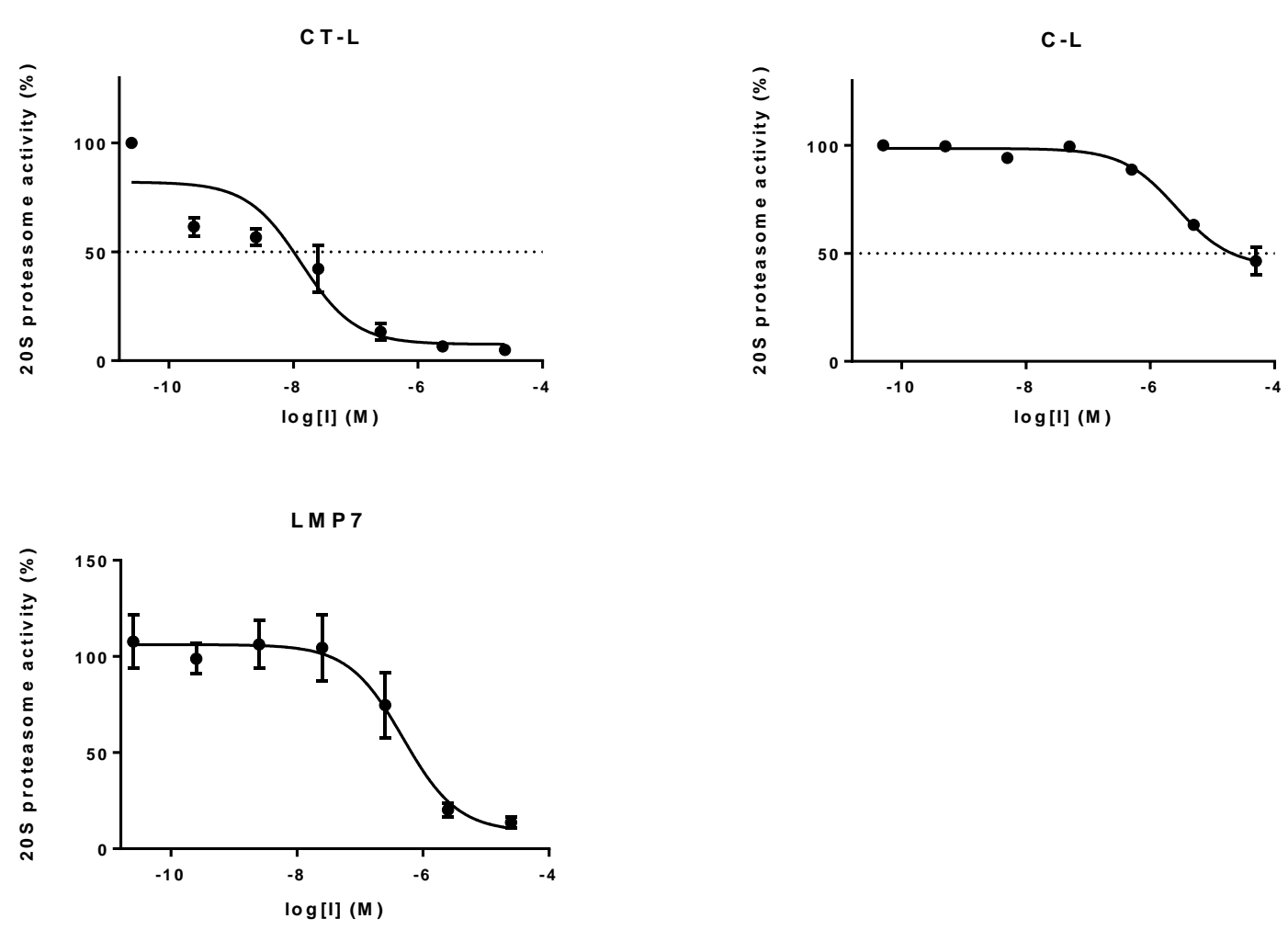

Supplementary Figure S1: Dose response curves- Compound 2b
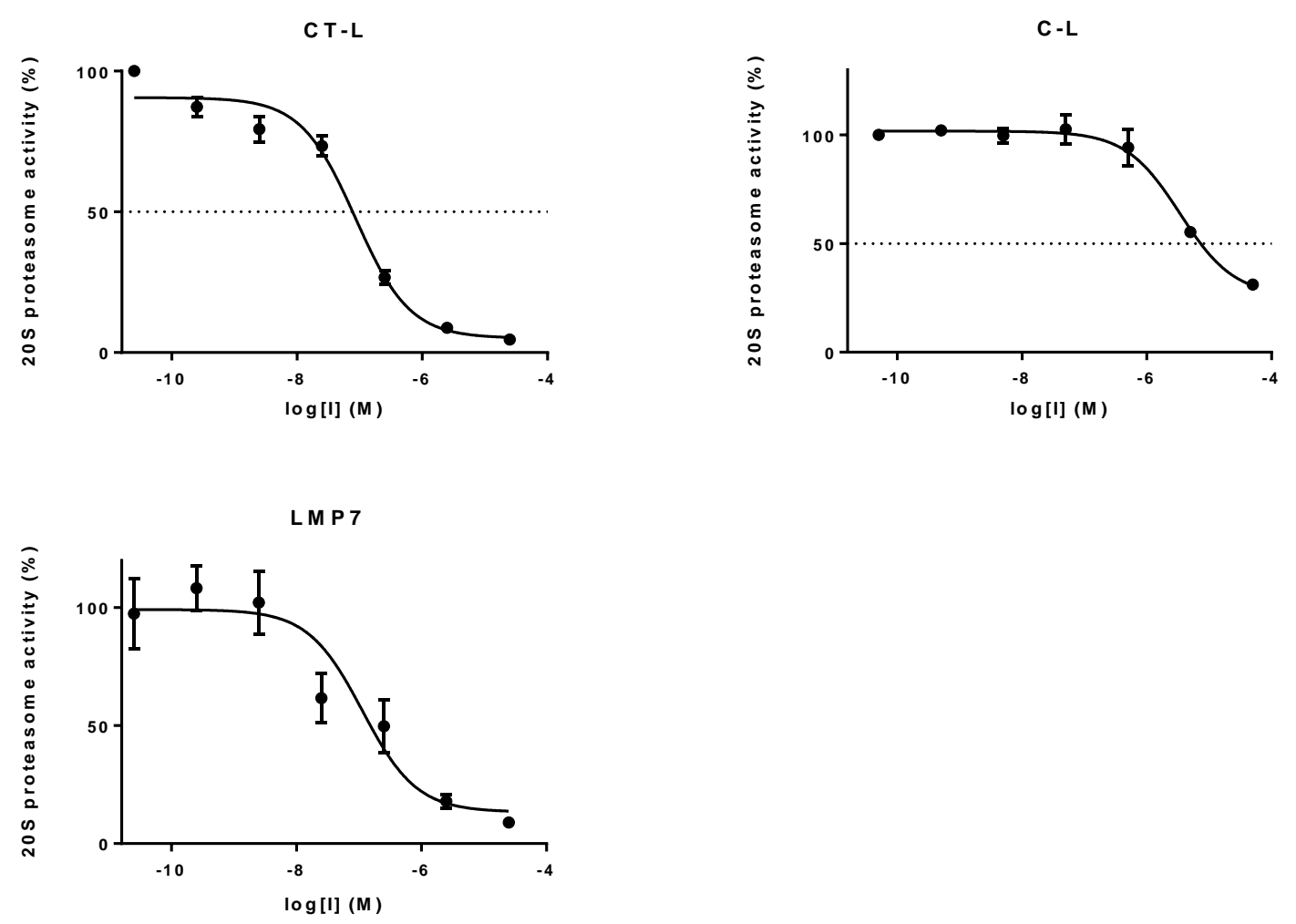

Supplementary Figure S1: Dose response curves- Bortezomib 

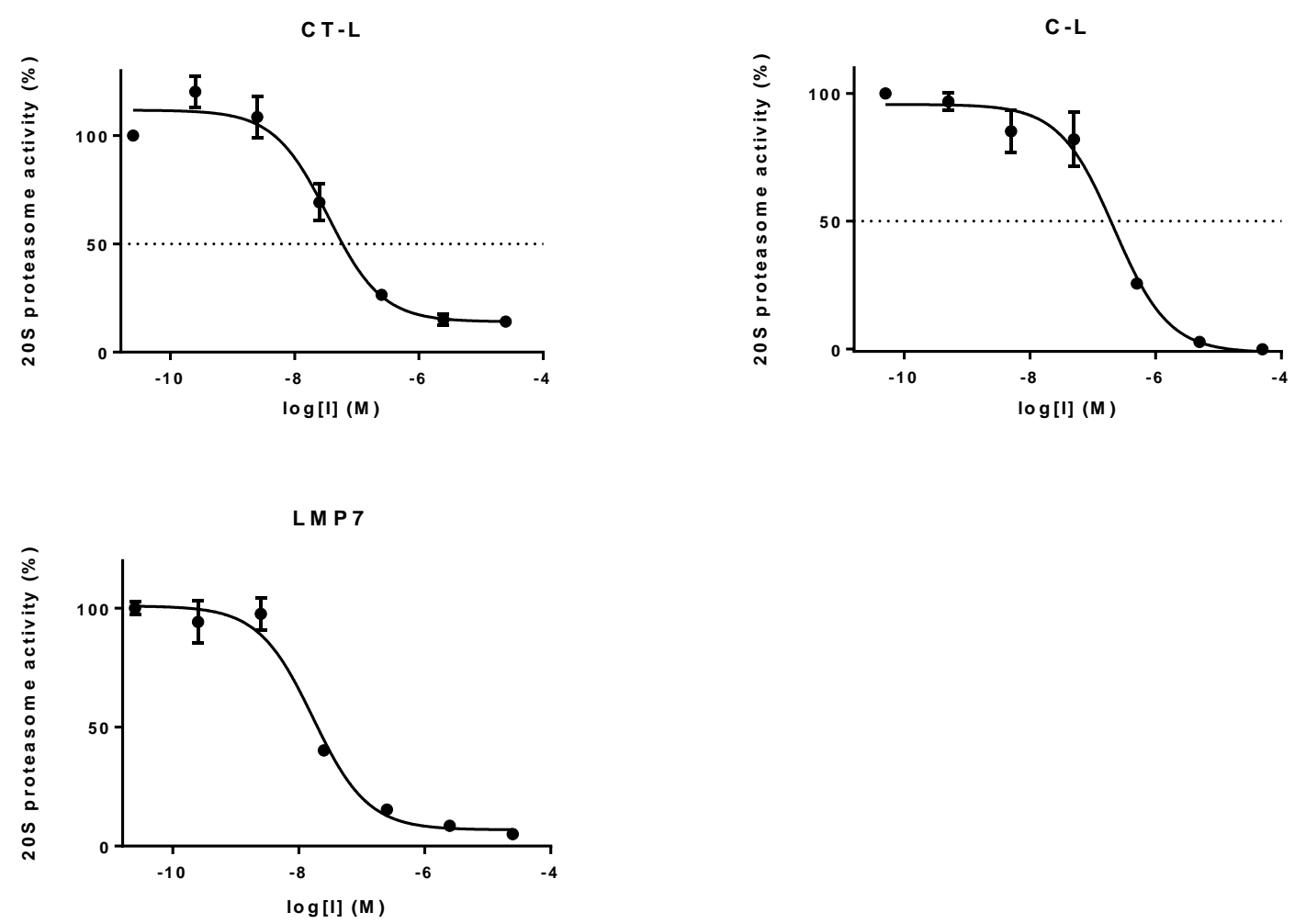

Supplementary Figure S1: Dose response curves- Carfilzomib

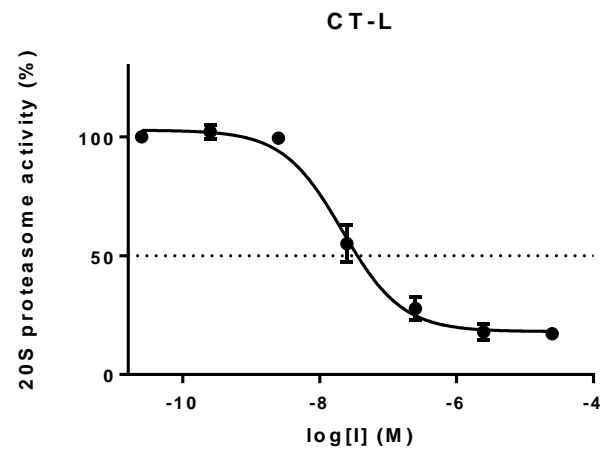

Supplementary Figure S1: Dose-response curves for proteasome inhibitors on purified rabbit 20S proteasome and mouse immunoproteasome. The purified proteasome was incubated with the indicated concentrations of bortezomib, carfilzomib, compounds 1a,b and 2a,b and specific AMC-tagged peptide substrates (Suc-Leu-Leu-Val-Tyr-AMC for CT-L and LMP7, Bz-Val-Gly-Arg-AMC for T-L and Ac-nLPnLD-AMC for C-L) for $2 \mathrm{~h}$. Hydrolysed AMC was subsequently detected with the Synergy ${ }^{\mathrm{TM}} \mathrm{H} 4 \mathrm{Hybrid}$ Multi-Mode

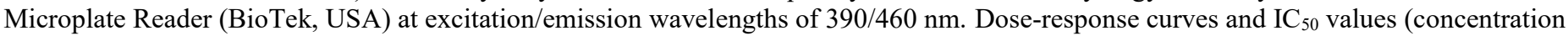
of proteasome inhibitor required to inhibit $50 \%$ of enzyme activity) were calculated using GraphPad Prism software (GraphPad Software Inc). 
k. Dose-response Curves for Cell Cytotoxicity Experiments

Supplementary Figure S2: Dose response curves- Compound 1a
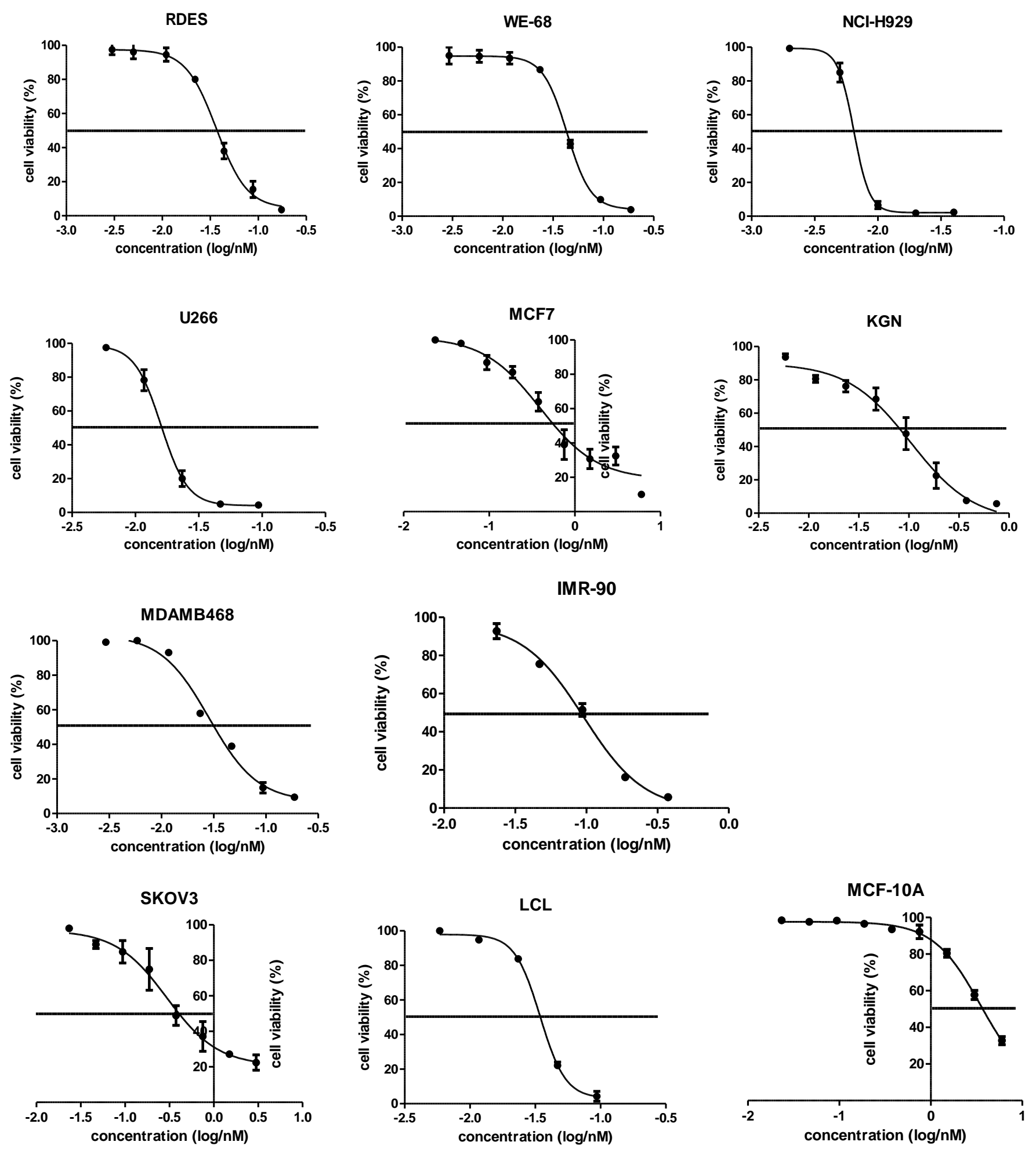
Supplementary Figure S2: Dose response curves- Compound 2a
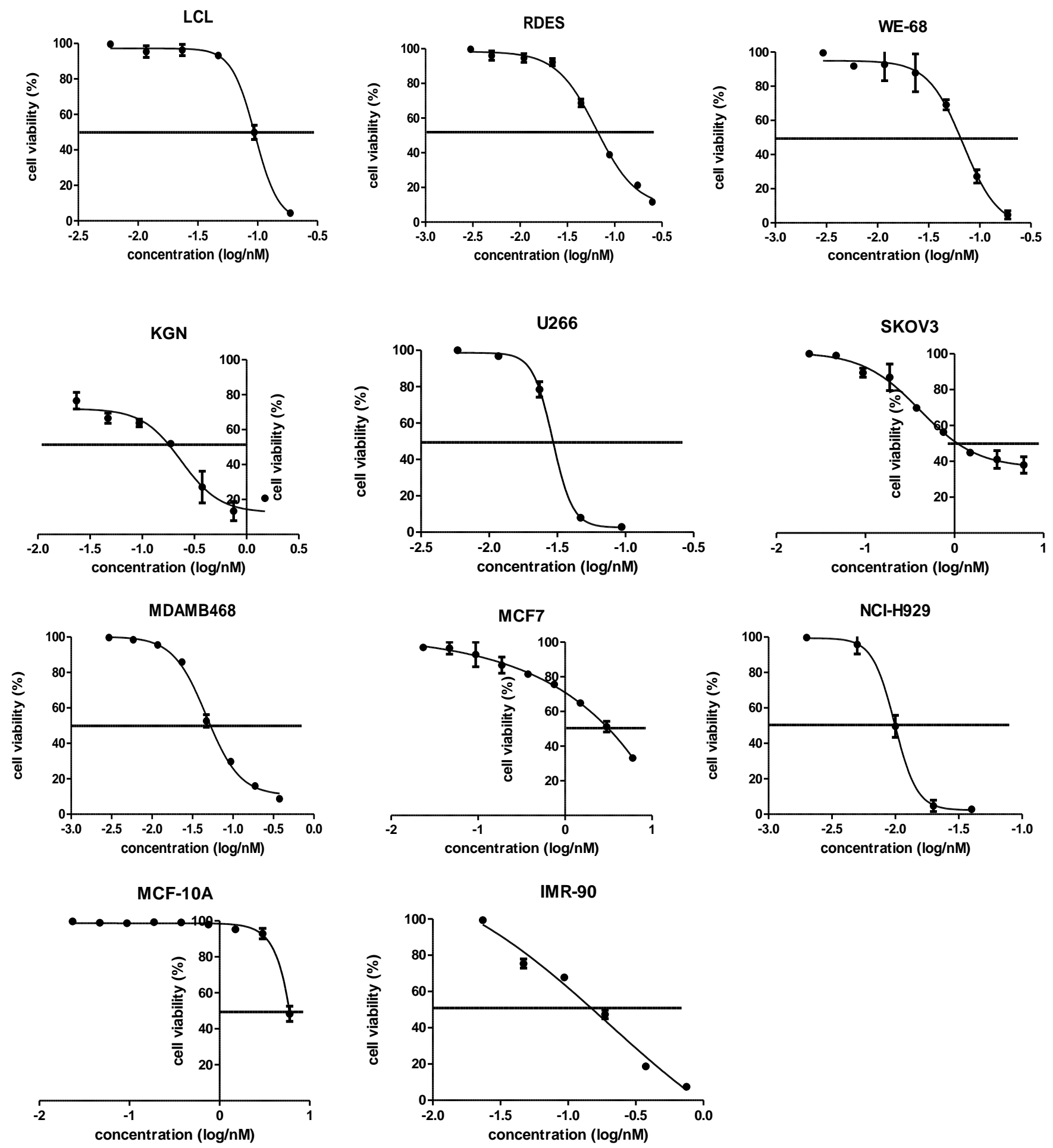
Supplementary Figure S2: Dose response curves- Compound 1b
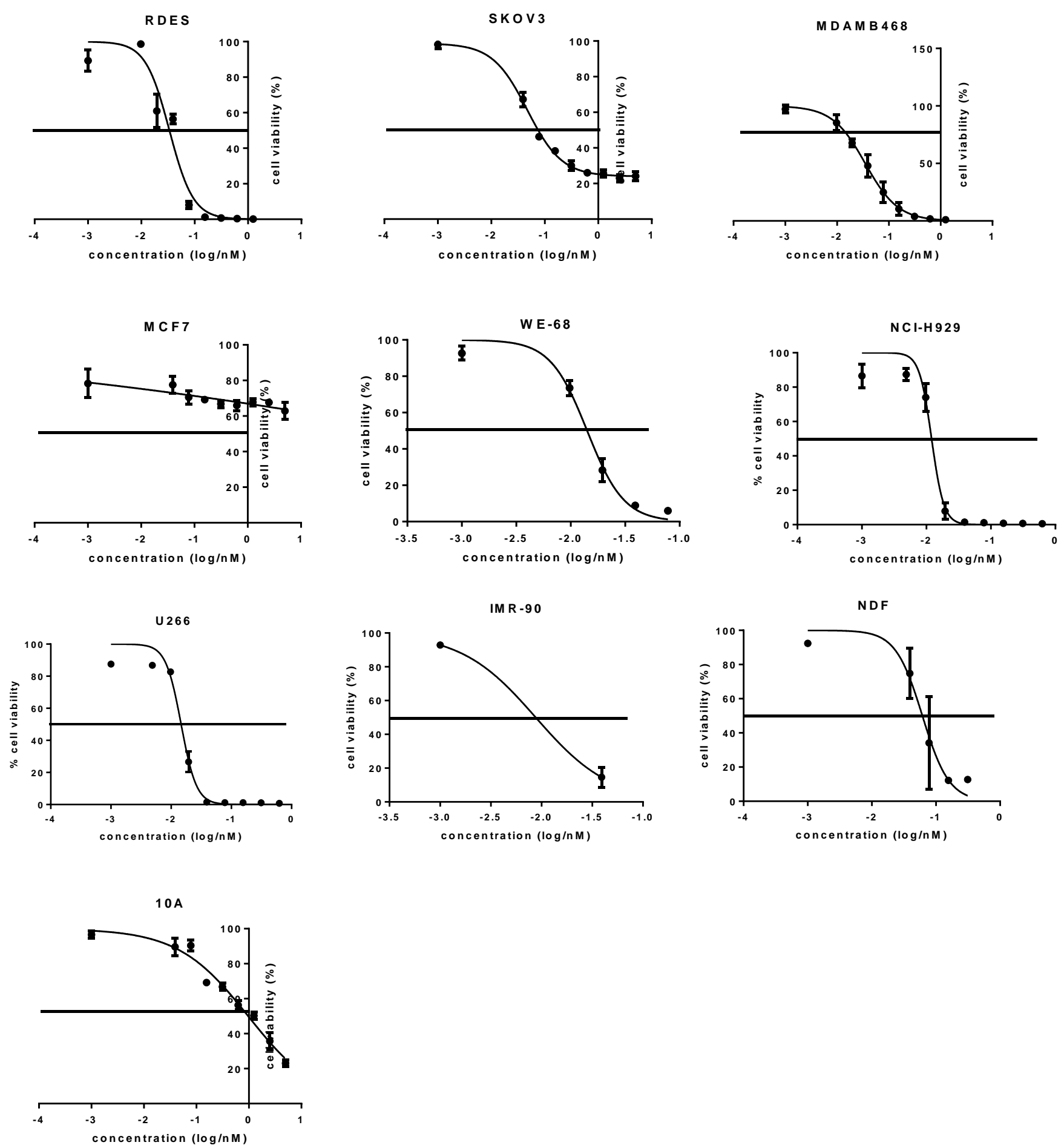
Supplementary Figure S2: Dose response curves- Compound 2b
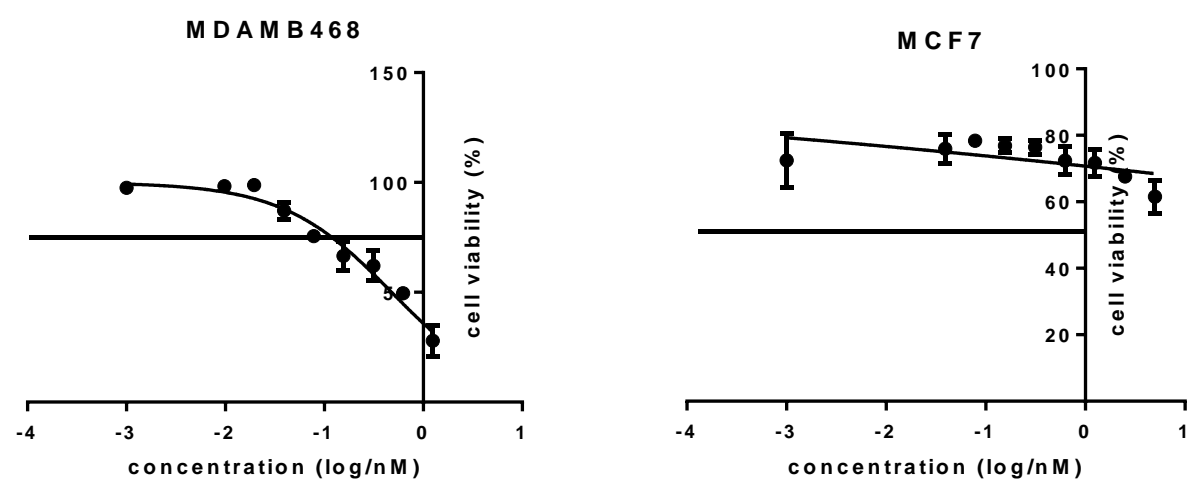

Supplementary Figure S2: Dose response curves- Bortezomib

LCL

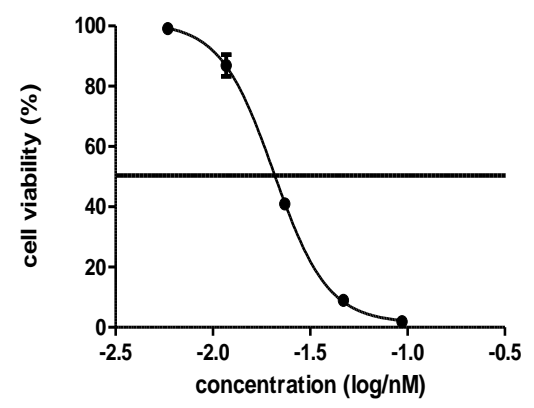

RDES
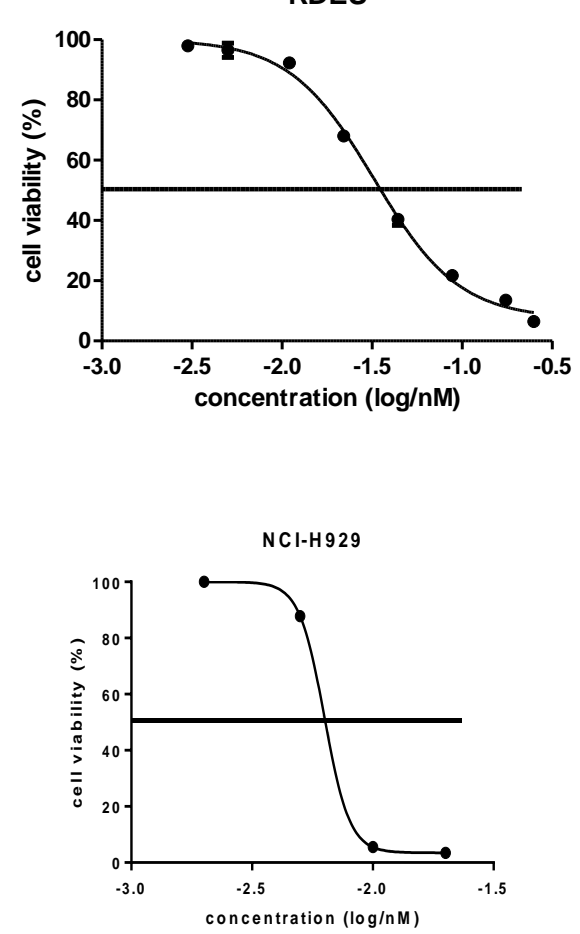

SKOV3

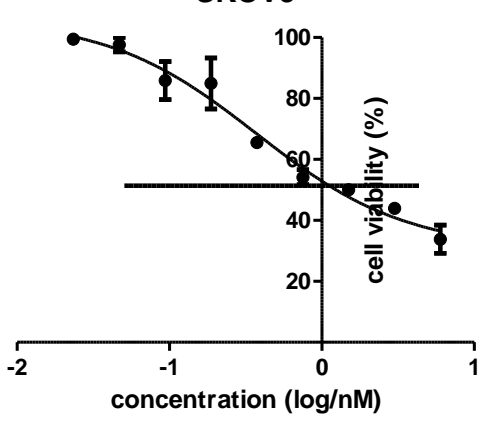

MCF7

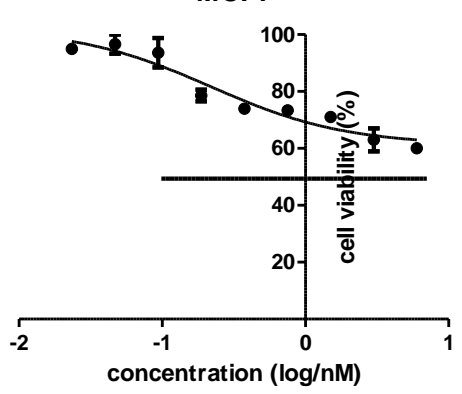

WE-68

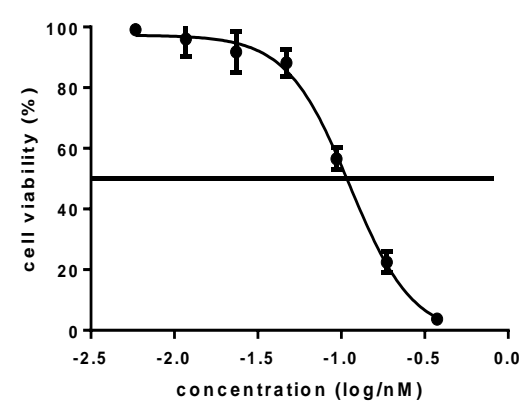

MDAMB468

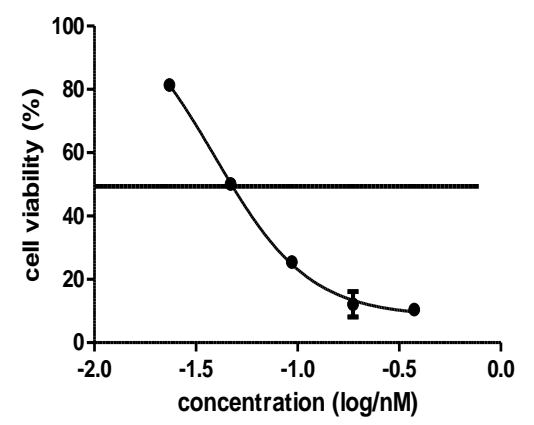

U266

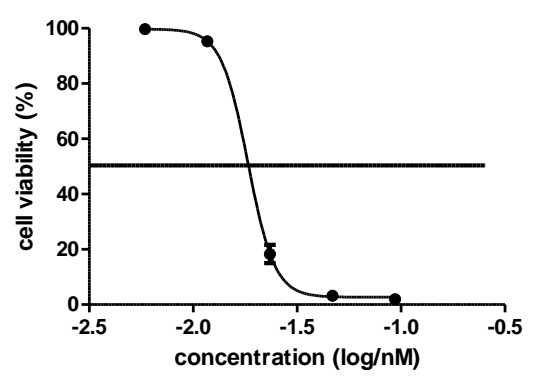

KGN

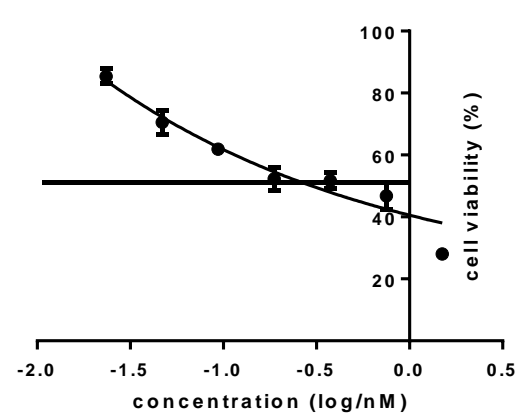



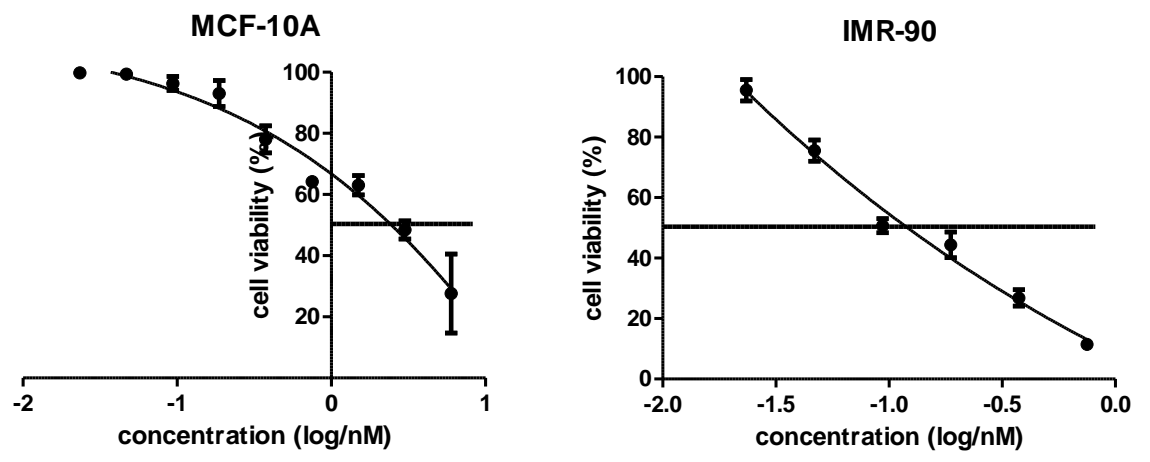

Supplementary Figure S2: Dose response curves- Carfilzomib

LCL

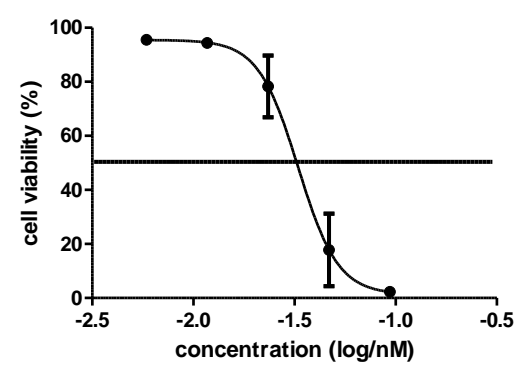

SKOV3

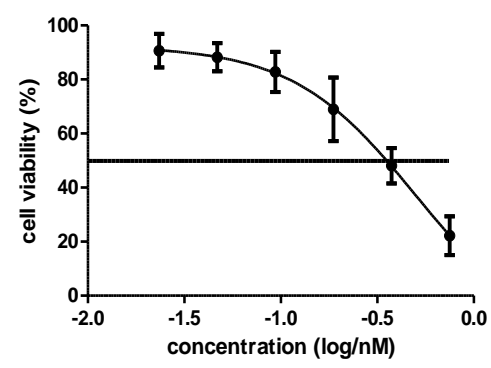

RDES

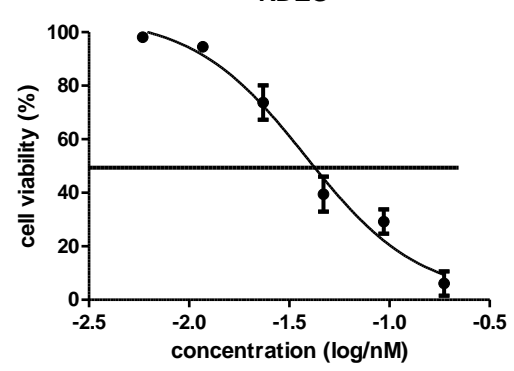

MDAMB468

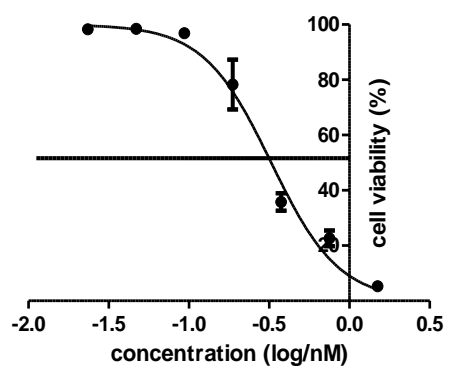

KGN

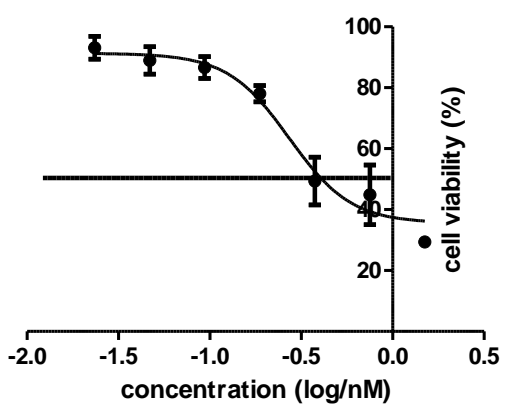

WE-68

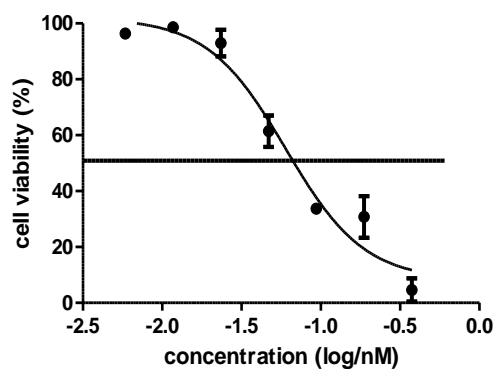




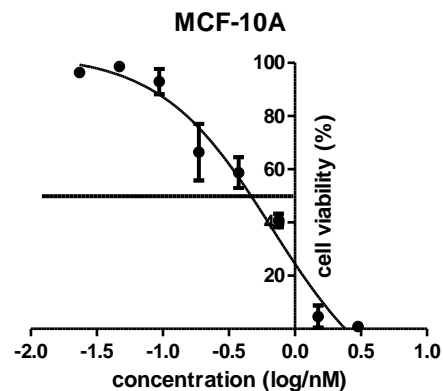

IMR-90

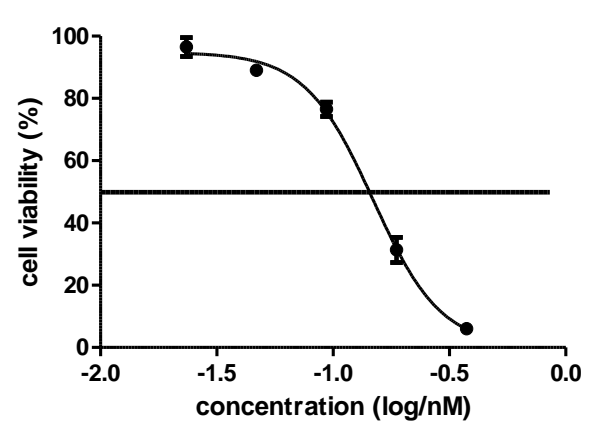

U266

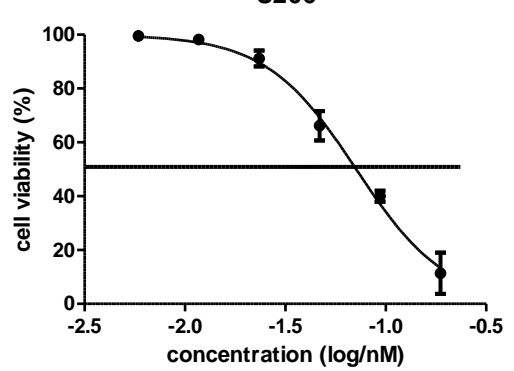

DSF

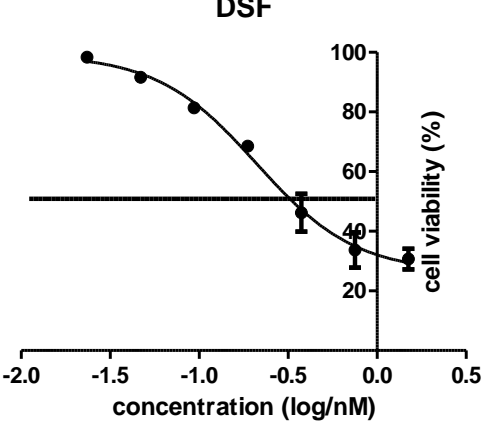

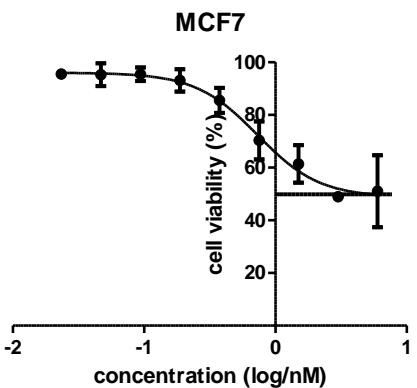

concentration $(\log / \mathrm{nM})$

Supplementary Figure S2: Dose-response curves for proteasome inhibitors on a panel of normal and cancer cell lines. WE-68 and RDES Ewings sarcoma cells, KGN and SKOV3 ovarian cancer cells, NCI-H929 and U266 multiple myeloma cells, MDAMB468 and MCF7 breast carcinoma cells (cancer cells) or primary lung and skin fibroblasts, immortalized non-malignant MCF10A or normal blymphoblastoids (normal cells) and were incubated with the indicated concentrations of bortezomib, carfilzomib, compounds 1a and 2a for 48 hours. The viability of the cell cultures was subsequently assessed following the protocol outlined in the Materials and Methods. Doseresponse curves and $\mathrm{IC}_{50}$ values (concentration of proteasome inhibitor required to kill $50 \%$ of cells) were calculated using GraphPad Prism software (GraphPad Software Inc).

\section{Ubiquitin Accumulation Western Blot for Compounds 1a, 2a, Bortezomib and Carfilzomib}

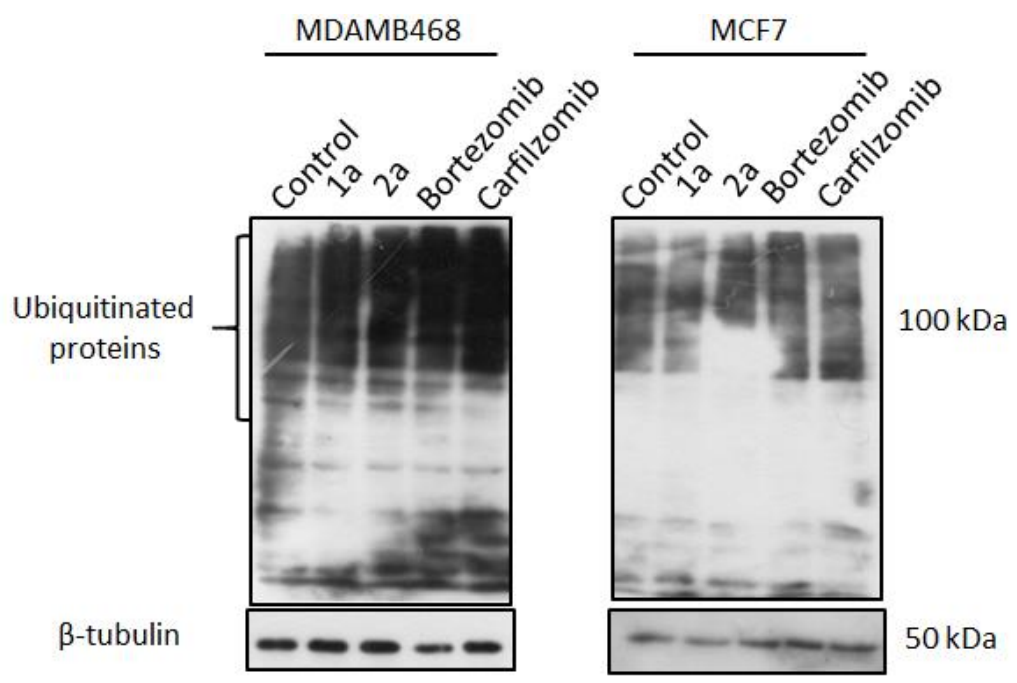

Supplementary Figure S3. Compounds 1a and 2a induce accumulation of high molecular weight ubiquitin conjugates. MDAMB468 and MCF7 were treated with $35 \mathrm{nM}$ of compounds 1a, 2a, bortezomib or carfilzomib for $4 \mathrm{~h}$, and Western blots of cell homogenates hybridised to an anti-ubiquitin antibody. $\beta$-tubulin was used as a loading control. 


\section{References:}

1.Dixon, M., The determination of enzyme inhibitor constants. Biochem. J. 1953, 55 (1), 170-171.

2.Neilsen, P. M.; Pehere, A. D.; Pishas, K. I.; Callen, D. F.; Abell, A. D., New 26S proteasome inhibitors with high selectivity for chymotrypsinlike activity and p53-dependent cytotoxicity. ACS Chem. Biol. 2013, 8 (2), 353-9.

3.Pishas, K. I.; Adwal, A.; Neuhaus, S. J.; Clayer, M. T.; Farshid, G.; Staudacher, A. H.; Callen, D. F., XI-006 induces potent p53-independent apoptosis in Ewing sarcoma. Sci. Rep. 2015, 5, 11465.

4.Zhu, Y.; Zhao, X.; Zhu, X.; Wu, G.; Li, Y.; Ma, Y.; Yuan, Y.; Yang, J.; Hu, Y.; Ai, L.; Gao, Q., Design, Synthesis, Biological Evaluation, and Structure, àíActivity Relationship (SAR) Discussion of Dipeptidyl Boronate Proteasome Inhibitors, Part I: Comprehensive Understanding of the SAR of EE-Amino Acid Boronates. J. Med. Chem. 2009, 52 (14), 4192-4199.

5.Chua, K. C. H.; Pietsch, M.; Zhang, X.; Hautmann, S.; Chan, H. Y.; Bruning, J. B.; Gütschow, M.; Abell, A. D., Macrocyclic Protease Inhibitors with Reduced Peptide Character. Angew. Chem. Int. Ed. 2014, 53 (30), 7828-7831. 